\title{
OBSERVATIONS ON HPHT-GROWN SYNTHETIC DiamondS: A ReVIEW
}

Sally Eaton-Magaña, James E. Shigley, and Christopher M. Breeding

This article presents statistical data and distinctive features for several thousand HPHT-grown synthetic diamonds examined by GIA from 2007 through 2016. This study, the first comprehensive summary published on such a large number and wide variety of samples, describes the reliable means of identifying them, with a focus on material currently marketed for jewelry use. The color of HPHT synthetic diamonds analyzed by GIA has shifted noticeably during this time-in the early years, orange-yellow, yellow, and yellow-orange samples comprised the overwhelming majority, while colorless and blue samples are much more prevalent today. HPHT synthetics are making inroads into the large diamond market, with cut stones larger than 10 carats, as well as the colorless melee market, where small HPHT synthetics are being mass-produced in China. HPHT synthetics can be identified by their distinctive fluorescence patterns using the DiamondView luminescence imaging instrument, the lack of "strain" (anomalous birefringence) when viewed through crossed polarizers, and to a lesser extent by the detection of various features in photoluminescence (PL) spectroscopy. This material may also display magnetism and a short-wave fluorescence and phosphorescence reaction that are inconsistent with similarly colored natural diamonds.

ynthetic gem diamonds grown by the high-pressure, high-temperature (HPHT) process have been commercially available since the mid1990s. This article presents statistical information and distinctive identification features based on a review of data gathered by GIA, principally at the New York and Carlsbad laboratories, for several thousand HPHT-grown synthetic diamonds. This study includes all HPHT synthetic diamonds submitted to GIA between 2007 (the year GIA started issuing Synthetic Diamond Grading Reports) and 2016. No summary has been published on such a large number of HPHT synthetic samples. We describe here the diagnostic means of identification, with an emphasis on the goods currently being sold for jewelry use. Box A details some of the most important identification criteria that may be used by gemologists.

Of this sample set, $12 \%$ were colorless to nearcolorless (D-J), $12 \%$ blue, $13 \%$ yellow, $4 \%$ pink to red, and 54\% yellowish orange to orangy yellow (e.g., figure 1). The remaining $5 \%$ showed other colors, in-

See end of article for About the Authors.

Gems \& Gemology, Vol. 53, No. 3, pp. 262-284,

http://dx.doi.org/10.5741/GEMS.53.3.262

(C) 2017 Gemological Institute of America cluding green-yellow and brown-orange. This set represents both as-grown and treated colors. While some samples were purchased by GIA on the market or from manufacturers, or were loaned or donated to us by manufacturers for study purposes, most were sub-

\section{In Brief}

- Colors, sizes, and other properties of HPHT synthetic diamonds submitted to GIA's laboratory have changed over the past decade.

- Advances in growth techniques have led to more very large ( $>2 \mathrm{ct})$ and very small $(<0.05 \mathrm{ct})$ colorless synthetic diamonds in the trade.

- Identification methods for HPHT synthetics have remained consistent and reliable.

- HPHT synthetic diamonds have become more prevalent, and their market share will likely continue to expand.

mitted to GIA in polished form for identification or grading reports. To the best of our knowledge, this sample set is representative of the gem-quality HPHT synthetic material available in the trade. 


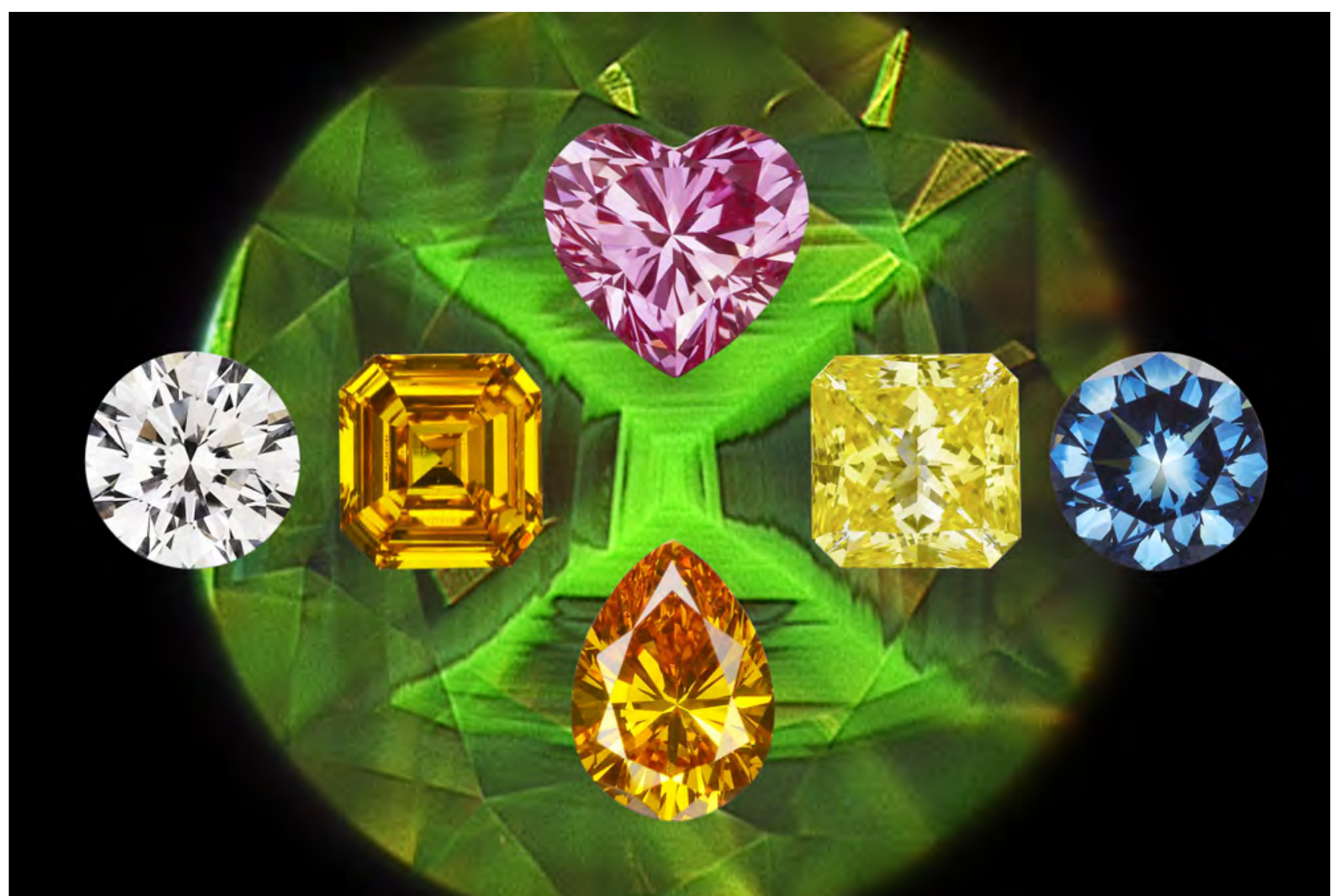

Figure 1. This collection of HPHT synthetics shows the major color products. The background is a DiamondView image with a cross-shaped fluorescence pattern, a well-known diagnostic feature of HPHT synthetics.

The evolution of HPHT synthetics has been detailed in previous $G \oplus$ ) $G$ articles (Shigley et al., 2002, 2004; D'Haenens-Johannsson et al., 2014, 2015) and Lab Notes entries (e.g., Ardon and Batin, 2017; Johnson et al., 2017) that include diamonds within this dataset. Whereas earlier studies examined small batches of material from specific manufacturers (which were likely grown using a similar recipe or HPHT pressure equipment), the goal of the present study is to investigate trends in the distinctive features seen among HPHT synthetic diamonds from multiple sources over the past ten years.

During the decade covered in this review, the colors of HPHT synthetics have shifted from predominantly yellow and orange to colorless and blue. The early years (2007-2008) likely represent the colors manufactured during the prior decade. The high number of submissions in those early years represents material that had already been available in the trade-for example, synthetics in the yellow, green, pink, and blue color ranges discussed by Shigley et al. (2004). There has also been a dramatic expansion in the size ranges. This includes polished gems greater than 10 carats (although production is still limited), as well as a significant increase in the output of HPHT synthetic melee, whose volume and small stone size present particular identification problems for the jewelry trade.

\section{HPHT SYNTHETIC DIAMOND GROWTH}

High-pressure, high-temperature diamond growth was first announced by the General Electric Company (GE) in 1955, and today most HPHT synthesis has its origins in the temperature gradient method first developed in 1959 (Bovenkerk et al., 1959). Yet it was only during the 1990s that these products attained sufficient size and gem quality to present significant concerns to the jewelry industry (Shigley et al., 1997). High-pressure reactor chamber design and control of diamond growth parameters have advanced considerably in recent years. The consistent production of larger as well as colorless HPHT synthetics is now possible, and several HPHT synthetic crystals can be grown simultaneously within the 


\section{Box A: IDENTIfication CRITERIA fOR the GeMOlOGiSt}

While HPHT synthetic diamonds can show several distinctive visual features that aid a gemologist in identification, few features will unambiguously confirm that a diamond is not an HPHT-grown synthetic. Therefore, a negative result does not exclude HPHT synthetic origin. For example, while magnetism is a strong indicator of HPHT growth, a lack of magnetism does not exclude the possibility. Reliable conclusions regarding natural or synthetic origin should be made from a combination of gemological and spectroscopic data, and the origin is probably best determined by a gemological laboratory. The features mentioned below have all been described and illustrated in the published literature.

Strain. The lack of observable strain (anomalous birefringence) when a diamond is viewed with polarized light does provide a strong indication of HPHT growth (figure A-1). Natural diamonds are typically subjected to varying stresses during their long growth and transport history. In contrast, HPHT synthetic diamonds are grown in a uniform high-pressure field. Yet the presence of birefringence does not eliminate synthetic origin, as CVD-grown diamonds commonly show strain and HPHT-grown diamonds rarely do (Ardon and Batin, 2017).

Magnetism and Metallic Inclusions. HPHT synthetics span the clarity scale, but those examined by GIA trend toward higher clarity grades (see "Analysis of Quality Grading Factors," figure 6). Due to the flux-metal chemistry necessary for HPHT growth, any observable features, such as metallic inclusions (see figure 8), are usually evidence of a distinctive growth environment. Such metallic inclusions are rarely observed in natural diamonds (Smith et al., 2016). Occasionally, metallic inclusions are present in sufficient concentration in a synthetic diamond to produce a detectable magnetic reaction. The absence of these metallic inclusions, or the absence of a magnetic response, does not exclude HPHT synthetic origin, as research has shown that the magnetic attraction was consistently detected only in the SI-I clarity range (D'Haenens-Johansson et al., 2014). A diamond dealer once related to us the prac-

Figure A-1. Viewed in crossed polarizers, natural diamonds (left) and CVD synthetics (middle) display higherorder interference colors than those generally seen in HPHT synthetics, which tend to display uniform, featureless birefringence (right). Shown in these photos are a $3.49 \mathrm{ct} \mathrm{D-color} \mathrm{natural} \mathrm{diamond} \mathrm{(left),} \mathrm{a} 2.51 \mathrm{ct} \mathrm{H}$-color CVD synthetic (middle), and a 0.46 ct D-color HPHT synthetic (right).
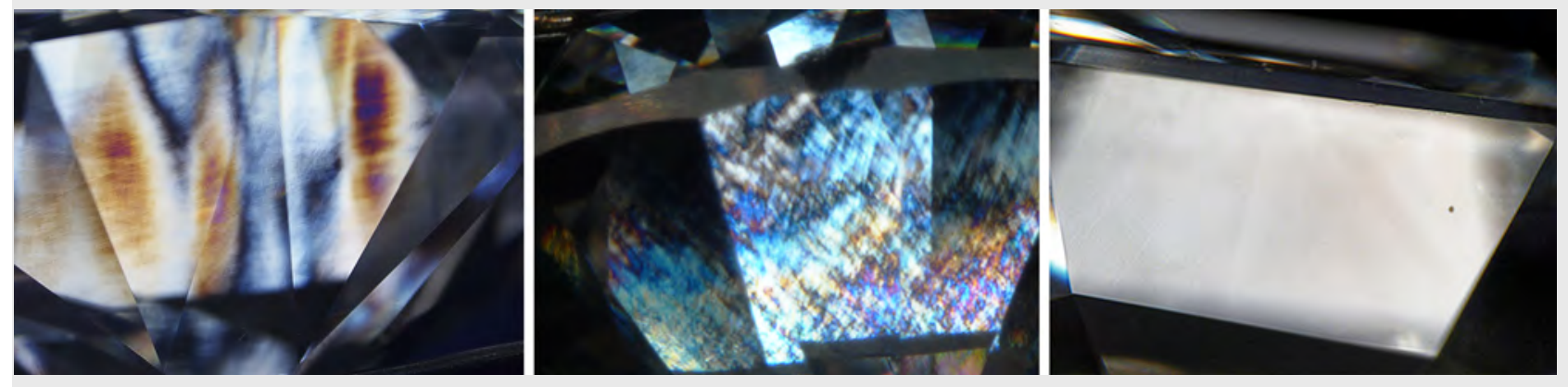

press (D'Haenens-Johansson et al., 2015). In general, HPHT growth proceeds at temperatures and pressures designed to approximate the conditions of natural diamond growth. Within the earth, diamonds generally form at pressures of 5.5-8.0 GPa $(55,000-$ 80,000 atmospheres) and temperatures of 1000 $1400^{\circ} \mathrm{C}$, corresponding to depths of $140-240 \mathrm{~km}$ (Shirey and Shigley, 2013).

In HPHT growth, a carbon source such as graphite or diamond powder is placed in the reactor chamber along with other ingredients to facilitate diamond growth atop a diamond seed. A molten metal catalyst (usually containing a mixture of $\mathrm{Fe}, \mathrm{Ni}, \mathrm{Co}$, or other elements) allows growth to proceed at a lower temperature. This also reduces the technological complexity and some of the expense required to grow diamond under HPHT conditions. HPHT growth occurs at pressures of 5-6 GPa (roughly equivalent to the pressure exerted by a commercial jet airplane if balanced on the tip of a person's finger) and at temperatures of 1300$1600^{\circ} \mathrm{C}$. As with CVD diamond growth, HPHT growth proceeds by creating a temperature gradient in which the carbon source is at a slightly higher temperature than the diamond growth seed. This causes the carbon atoms to diffuse through the molten flux toward the slightly colder section of the chamber to form a syn- 
tice of sweeping a magnet over a parcel of diamonds as a method for detecting synthetics. While this might have been considered adequate in prior decades, it is no longer a reliable test.

Color Zoning. Due to their growth methods, fancy-color HPHT-grown synthetics often have color zoning related to the arrangement of internal growth sectors, and the concentration of color-causing impurities like nitrogen or boron in some select sectors. The presence of such growth zoning patterns, particularly in diamonds with yellow, yellow-orange, or blue coloration, would strongly suggest an HPHT origin. Geometric patterns of color zoning are rarely seen in natural diamonds. Some natural diamonds with dark-colored zones are due to high concentration of graphitic inclusions (Hainschwang et al., 2014; Eaton-Magaña et al., 2016) rather than the variable incorporation of color centers as seen in HPHT synthetics.

Fluorescence. HPHT synthetic diamonds generally show a stronger fluorescence reaction to short-wave UV than to long-wave UV. This trend is observed for both fancycolor (Shigley et al., 2002, 2004) and colorless material (D'Haenens-Johansson et al., 2015). Interestingly, this observation appears to correlate with type $\mathrm{Ib}$ diamond, as King et al. (2005) reported that among the very few natural diamonds that show a similar reaction, almost all were type Ib. The predominant fluorescence colors are green to yellow to orange. Additionally, the vast majority of HPHT synthetics in the "colorless" range exhibit no detectable fluorescence to long-wave UV.

Phosphorescence. As phosphorescence is often quite weak, the reaction is best observed in a darkened room. The observed duration can persist from less than a second to a few tens of seconds. Blue and colorless HPHT-grown synthetics often show light blue phosphorescence, with the luminescence spectral band centered at $500 \mathrm{~nm}$. In this color range, orange phosphorescence at $575 \mathrm{~nm}$ is occasionally observed in HPHT synthetics but is thought to be exclusive to this material (Watanabe et al., 1997; Eaton-Magaña and Lu, 2011). The $500 \mathrm{~nm}$ phosphorescence band due, in part, to the presence of boron is commonly observed in both type IIb natural diamonds and CVD synthetics, but the phosphorescence is generally less intense.

Diamond Type. Colorless samples that are UV transparent or show no detectable nitrogen in their FTIR absorption spectra-meaning they are type II-should always be sent to a gemological laboratory for testing, as these might have been subjected to HPHT processing or could be CVD or HPHT synthetic diamonds.

Inscription. Major HPHT synthetic manufacturers often inscribe the origin on the girdle (e.g., "Lab Grown" or other wording). However, the lack of an inscription does not necessarily indicate a natural stone, as diamonds can be recut or a manufacturer might not inscribe the synthetic origin.

Advanced Testing. Gem testing laboratories should maintain a full complement of gemological, imaging, and spectroscopic instrumentation, including a DiamondView imaging microscope, an FTIR absorption spectrometer, and a photoluminescence (PL) spectrometer equipped with several lasers. Additionally, these laboratories must have access to HPHT synthetics that are representative of products available in the trade and maintain a database of their properties. They must be constantly vigilant for emerging trends that deviate from standard detection criteria for natural, treated, or synthetic diamonds. Gem labs must also operate under the assumption that today's reliable criteria may not be applicable in the future, which would require alternative methods to ensure that identification keeps pace with the manufacturers' growth technology. thetic diamond crystal on the seed. Most early gemquality HPHT synthetics were fancy color, since colorcausing impurities, such as nitrogen (yellow) or boron (blue), were often prevalent within the growth system. Recent progress in growth technology has allowed for better control of impurity contents, resulting in the creation of colorless crystals (e.g., figure 2).

\section{ANALYSIS OF EXISTING DATA}

We will summarize quality factors, basic gemological properties, ultraviolet fluorescence reactions, and key spectral features based on information gathered when these several thousand HPHT-grown samples were examined by GIA between 2007 and 2016. In some instances, GIA did not collect all data types on a particular HPHT synthetic sample for various reasons: time constraints, the lack of certain instrument capabilities at the time of examination, or the need to limit the analysis to the grading service requirements requested by the submitting client. In the following discussion, therefore, we will indicate the percentage of total submissions for which that data was collected. Nonetheless, the information reported here represents the most substantial database of observations published to date on gem-quality HPHT synthetic diamonds. 


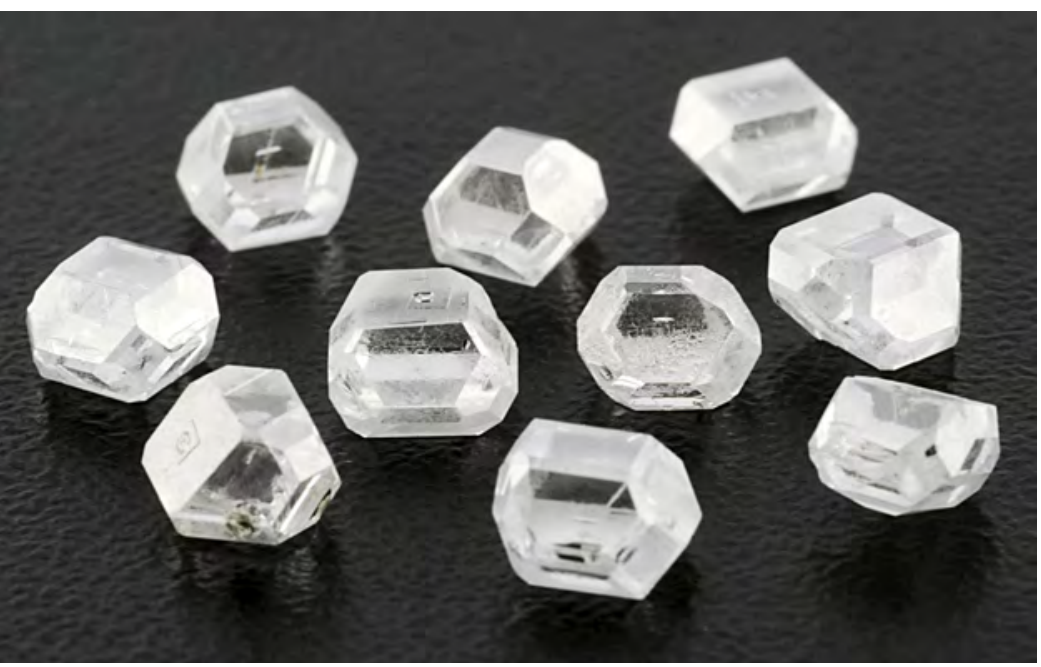

Figure 2. This selection of colorless HPHT synthetic crystals (0.50-0.69 ct) was grown by Jinan Zhongwu New Materials Company Ltd. of Shandong, China.

We noted no significant differences in characteristics between the HPHT synthetic samples sourced directly from the manufacturers and those submitted by GIA laboratory clients. The information presented here is strictly limited to HPHT synthetics examined by GIA, which might not represent all of the goods available within the gem trade and certainly not those crystals grown for technological or industrial applications.

\section{ANALYSIS OF QUALITY GRADING FACTORS}

Color. Since 2007, there has been a pronounced shift in the color of the HPHT synthetics submitted for grading. In the early years of GIA's Synthetic Diamond Grading Report, the overwhelming majority were orangy yellow to yellowish orange (in this article, this color range is shortened to "yellow-orange"; e.g., figure 3). The proportion of HPHT synthetics with pink coloration has remained generally constant at around $3-8 \%$. During the early years, blue samples were not submitted in large numbers. Since then, the blue and yellow hues have shown some fluctuations in annual percentage but exhibited no distinct trends. Colorless to near-colorless synthetics have shown a dramatic increase, now reaching $43 \%$ of the HPHT synthetics submitted to GIA in 2016. While the proportion of yellow-orange HPHT synthetics that have been submitted (and likely manufactured) has decreased in recent years, they still comprise a clear majority of the HPHT synthetics submitted to GIA from 2007 through 2016 (figure 3, right).

Among the colorless to light yellow (D-Z) HPHT synthetics, the vast majority $(72 \%)$ were in the colorless (D-F) range, while $26 \%$ were in the near-colorless (G-J) range, and the remainder had lower color grades. In contrast, most D-Z CVD synthetics examined by GIA were in the near-colorless range: $21 \%$ D-F, $67 \%$ G-J, and 10\% K-N (Eaton-Magaña and Shigley, 2016).

Figure 3. Left: The color distribution of HPHT synthetic diamonds analyzed by GIA, separated by year. Right: The overall distribution of HPHT synthetics submitted to GIA by bodycolor. Yellow-orange HPHT synthetics represented the vast majority of submissions during the early years and constitute a majority of all HPHT synthetics seen at GIA since 2007. In recent years, client submissions of yellow-orange HPHT synthetics have been eclipsed by blue and colorless samples. The percentage shown in red represents the portion of samples submitted for which data are available.

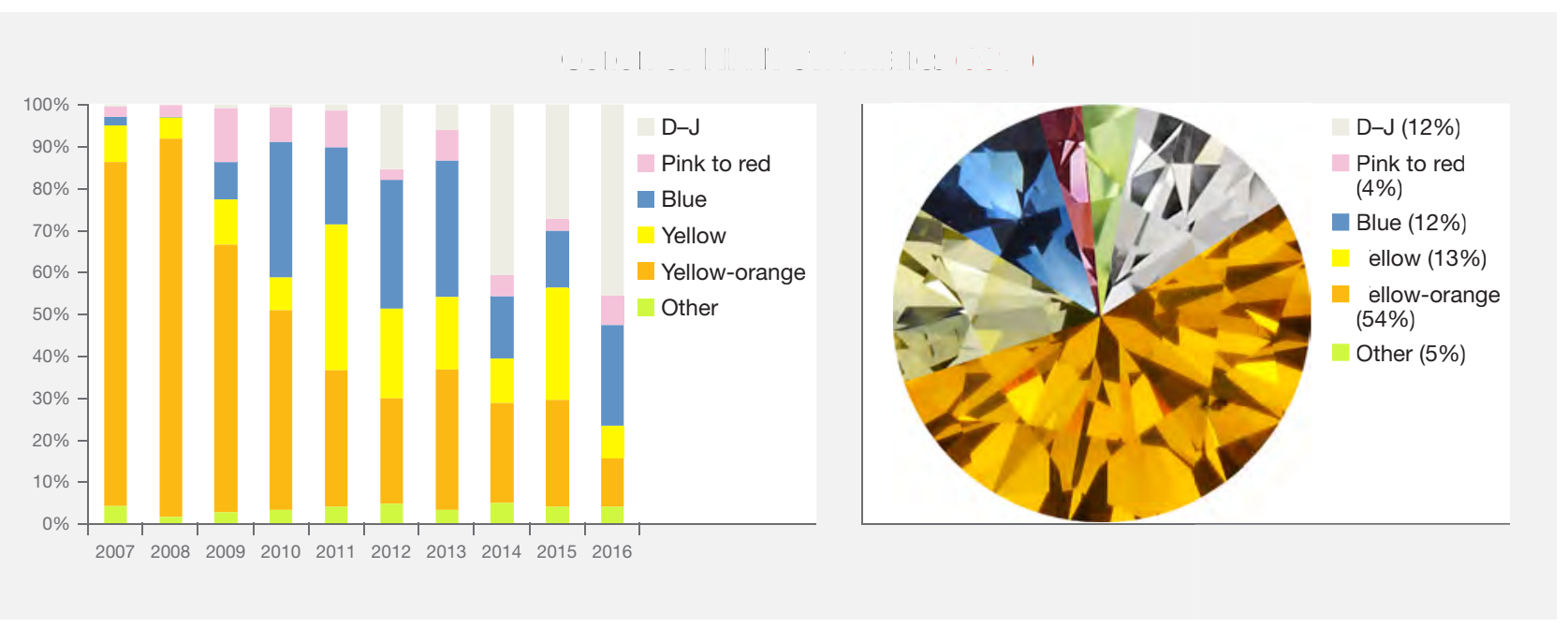




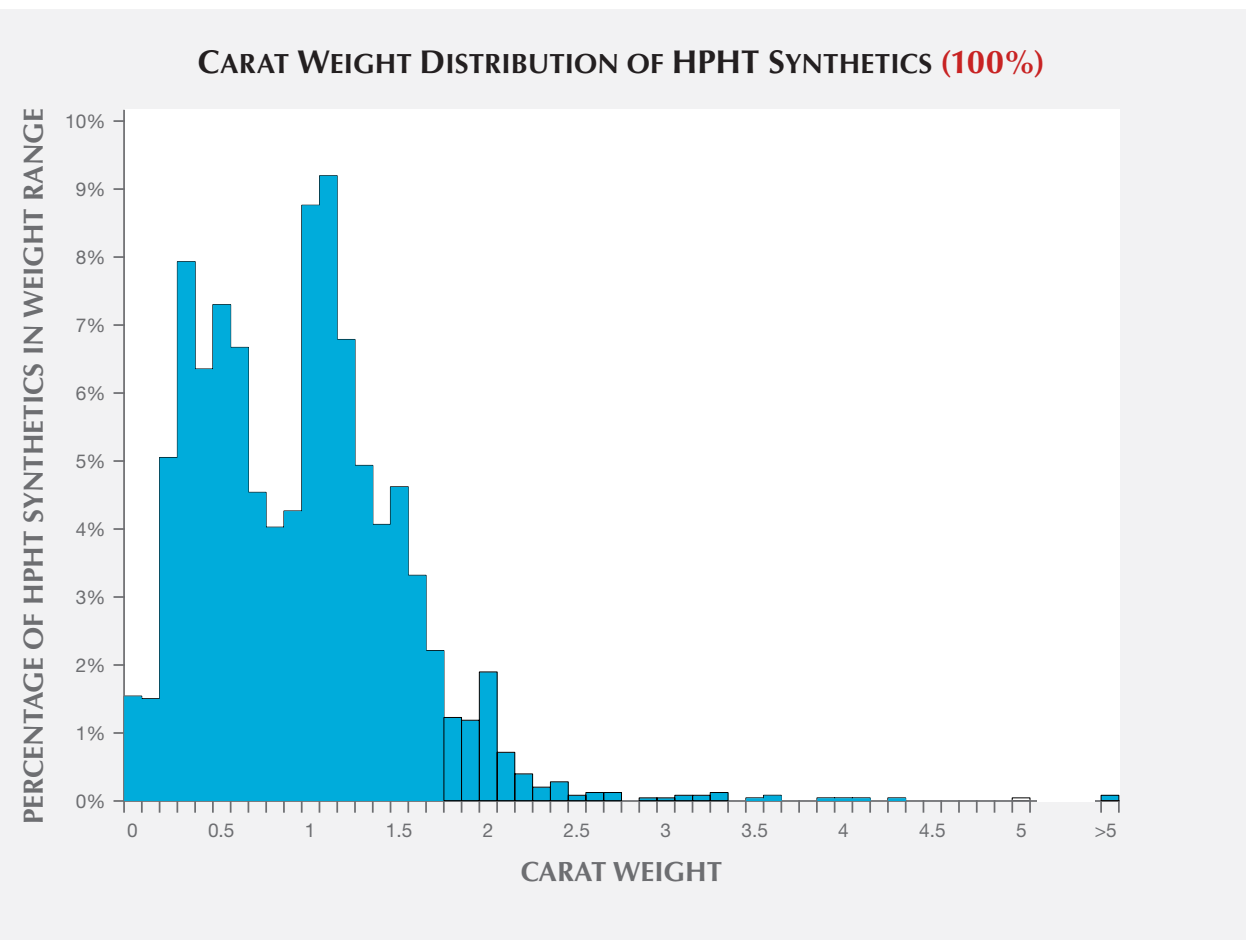

Figure 4. From 2007 through 2016, most of the HPHT synthetic diamonds analyzed by GIA were in the 0.2-0.5 and 1.0-1.5 ct range. The data here are divided into $0.1 \mathrm{ct}$ increments. The percentage shown in red represents the portion of samples for which data are available.

Most colors of HPHT synthetics are believed to be as-grown (i.e., due to impurities) rather than the product of post-growth treatment processing. In contrast, CVD synthetics are often subjected to postgrowth treatment. Most near-colorless CVD synthetics are subsequently HPHT treated (to remove any brown coloration), while the pink samples (the other major CVD product) undergo irradiation and annealing (Eaton-Magaña and Shigley, 2016).

The colors of "yellow-orange" and yellow HPHT synthetics are due to the presence of isolated nitrogen incorporated during the growth process (Shigley et al., 2002); however, the additional use of "nitrogen-getters" such as aluminum in the growth system can reduce the incorporation of nitrogen (Sumiya and Satoh, 1996). Almost all "orange" HPHT synthetics included a yellow component, while some contained a brown or pink modifier; very few were pure orange.

"Pink" HPHT synthetics (including purple-pink, red, and brown-red) owe their color to post-growth treatment by irradiation and low-temperature annealing. This procedure creates nitrogen-vacancy (NV) optical centers, which are also the source of color in treated pink diamonds, treated CVD synthetics, and the rare natural and untreated Golconda pinks.

Blue HPHT synthetics result from the presence of boron within the growth chamber. Colorless HPHT synthetics are reportedly sold as-grown without post- growth color modification (D'Haenens-Johansson et al., 2014), and they often contain small amounts of boron, which does not alter their color (but does impart luminescence).

Other less common colors include yellow-green to green samples. Green coloration has a number of origins in HPHT synthetics, including the presence of yellow zones (due to nitrogen) and blue zones (due to boron) that visually combine to give a greenish appearance (Shigley et al., 2004); laboratory irradiation after growth (Shigley et al., 2004); and high quantities of nickel impurities (Johnson et al., 2017).

Carat Weight. Faceted HPHT synthetics in the 1.001.50 ct range were the most common, representing $34 \%$ of those examined by GIA (figure 4). While HPHT synthetics larger than four carats have been newsworthy during the last few years, relatively few have been submitted, presumably due to very limited production. Additionally, the carat range distribution has not varied considerably from 2007 to 2016. Production of colorless melee has increased greatly in recent years (W. Wang, pers. comm., 2016), but so far no fancy-color synthetics of any size have been submitted to GIA in large numbers. With the announcement in late 2016 of a colorless melee sorting service, GIA has seen more of these very small synthetic diamonds; for more on HPHT synthetic melee, see box B. 


\section{Box B: HPHT Synthetic Diamond MeleE}

The market for near-colorless melee diamond (i.e., less than $0.05 \mathrm{ct}$ ) has traditionally been dominated by natural stones. However, dramatic improvements in HPHT growth technology and techniques in the past two or three years have had a profound effect on how jewelers must examine their stocks of melee-sized diamonds. HPHT synthetic diamond melee growth is quickly becoming a large industry in China (figure B-1, left). Factories full of HPHT presses can be found in the Chinese city of Zhengzhou, where companies can each produce more than 1,000 carats of near-colorless synthetic diamonds per day (W. Wang, pers. comm., 2016). After faceting, most of the synthetic melee weighs between 0.005 and $0.03 \mathrm{ct}$, with colors ranging from $\mathrm{D}$ to $\mathrm{N}$ and widely variable clarities (figure B-1, right).

The melee is grown as tiny, near-colorless individual crystals using even smaller yellow HPHT synthetic diamond seed crystals. Most of the rough is sold with the seed crystals still attached (figure B-2). Larger HPHT synthetic diamonds are grown upward from the $\{100\}$ cubic face of the seed crystal and have the cuboctahedral crystal form we have come to expect from HPHT-grown diamonds. While most of the HPHT synthetic melee crystals are also grown from a $\{100\}$ oriented seed, it is notable that several were grown from both $\{111\}$ octahedral and $\{110\}$ dodecahedral seed crystal faces as well (figure B-2). The crystals grown from $\{111\}$ and $\{110\}$ oriented seeds show a different form and external characteristics that might not be immediately associated with HPHT synthetics.
Near-colorless HPHT-grown melee share most of the key characteristics used to identify larger HPHT-grown synthetics, but their very small size often obscures visual features and makes spectroscopy difficult. All of the near-colorless synthetic melee known today are type II diamonds with no measurable nitrogen impurities. Some are type IIa, but in many cases trace boron impurities can be detected with FTIR analysis, classifying them as type IIb. The type IIa samples may also contain traces of boron that are below the detection level of most FTIR instruments. Although their fluorescence reaction to long-wave UV is usually very weak orange or not visible at all, the presence of boron gives rise to a very useful phosphorescence. When exposed to very high-energy short-wave UV, such as that of the DiamondView, all HPHT-grown melee diamonds will show some phosphorescence (usually blue) after the UV source has been turned off (figure B-3). Many of these synthetic melee contain metallic inclusions that are difficult to observe under the microscope in such small diamonds. In some cases, however, they are readily attracted to a magnet. Additionally, photoluminescence (PL) analysis reveals high concentrations of nickel-related defects in most HPHT synthetic melee and variable amounts of siliconrelated defects in some of them (D'Haenens-Johansson et al., 2014). These PL features rarely occur in natural diamond melee. Finally, DiamondView imaging reveals the individual growth zones typical of HPHT-grown synthetic diamonds, though the extremely small size of the melee often makes it difficult to clearly discern the pat-
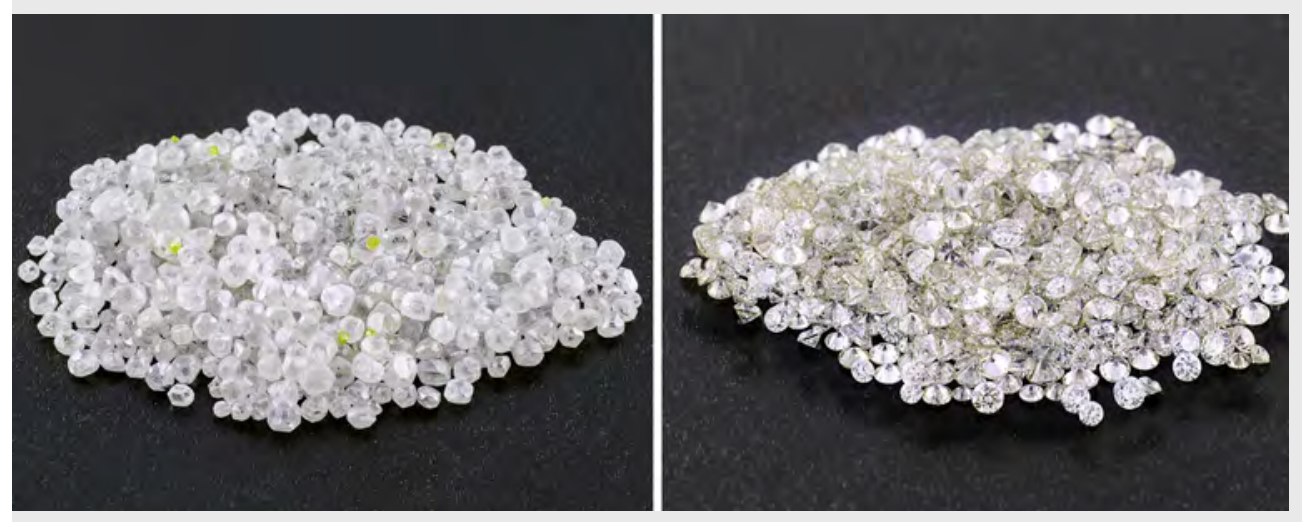

Figure B-1. Left: This assortment of 10 carats of near-colorless, HPHTgrown synthetic melee diamond crystals is typical of the material now being produced in China. Right: Most of the melee crystals are faceted into tiny round brilliants such as these, weighing about $0.01 \mathrm{ct}$ each. Photos by Wuyi Wang.

Since 2015, many of the previous records for carat weights of polished synthetic diamonds have been shattered (Deljanin et al., 2015; Wang and Poon, 2016). The Russian company New Diamond Technology has provided several colorless to near-colorless diamonds to GIA greater than five carats, along with several blue samples. This advancement has generated excitement as well as concern in the jewelry trade.

Cut. The majority of the faceted HPHT synthetics analyzed were round brilliants $(51 \%)$. Other common styles included square $(19 \%)$ and rectangle $(18 \%)$, with and without cut corners (figure 5, top). 
$\{100\}$

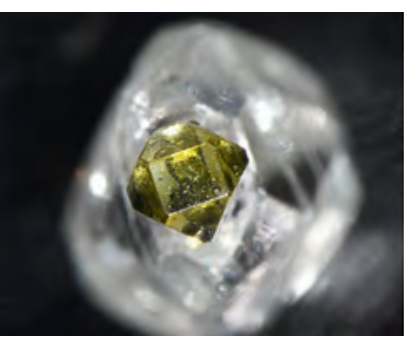

Cube

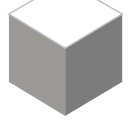

$\{110\}$

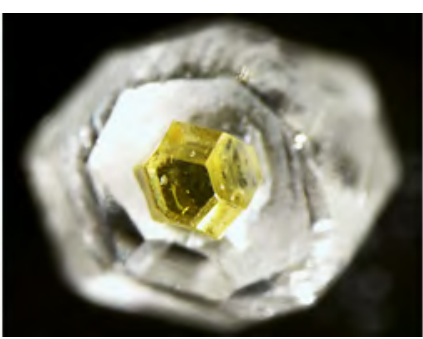

Dodecahedron

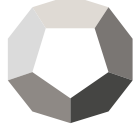

$\{111\}$

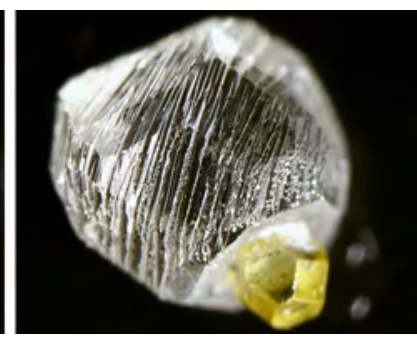

Octahedron

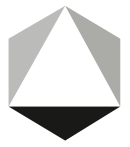

Figure B-2. Although most often grown from the $\{100\}$ cubic face of the seed crystal (left), some of the synthetic melee were grown from \{110\} dodecahedral (center) and $\{111\}$ octahedral (right) seed faces, giving rise to crystal forms and growth striations not typically associated with synthetic diamonds. Photos by Ulrika D'Haenens-Johansson. terns. In many cases, the patterns are slightly atypical, likely representing the growth using different faces of the seed crystal as described previously (figure B-4).

With the ever-expanding production of near-colorless, melee-sized HPHT-grown synthetic diamonds, the industry must be more vigilant than ever in understanding these tiny goods that are used to adorn jewelry. While

Figure B-3. Following exposure to a high-energy shortwave UV source, HPHT-grown synthetic melee diamonds tend to phosphoresce blue when the UV light is turned off. This effect is due to trace concentrations of boron impurities. Photo by Wuyi Wang.

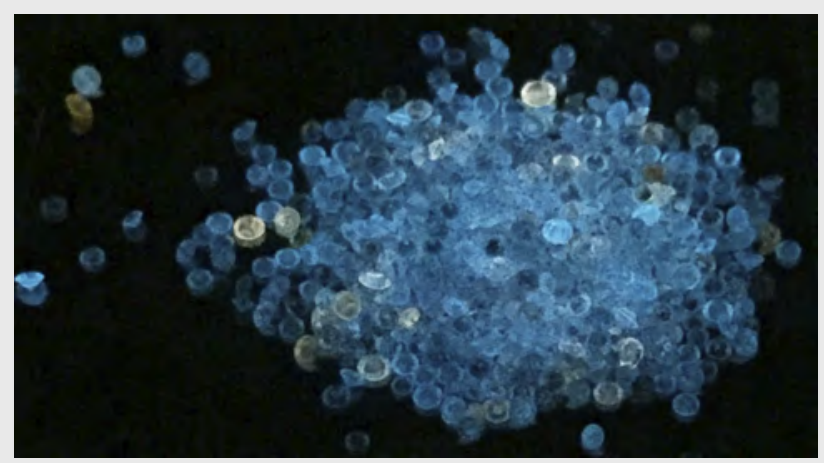

we have also examined some CVD-grown melee, most synthetic melee appears to be grown by HPHT methods. Many gemological laboratories now offer low-cost melee testing services to help with identification.

Figure B-4. Left: DiamondView fluorescence images reveal normal cuboctahedral growth patterns in most of the melee, though they are often difficult to observe in such small sizes. Right: Some of the melee show different patterns that may result from growth from atypical seed crystal faces. Photos by Christopher M. Breeding.
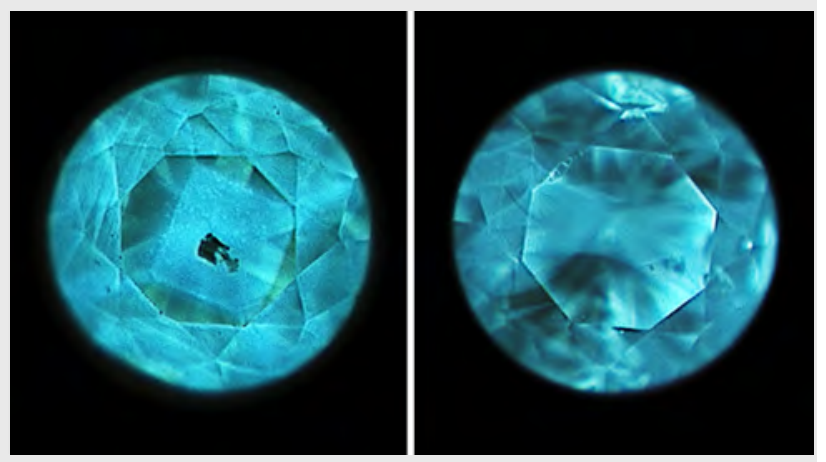

Manufacturers appear to have chosen the round brilliant cut because of the popularity of this style, even though a "fancy" shape would have retained slightly more weight from the original crystal.

Since GIA only assigns cut grades for D-Z color round brilliants, only a small percentage of the HPHT synthetics were eligible for such an assess- ment. Among these, 44\% received a Very Good cut grade, with 30\% Excellent and 24\% Good (figure 5, bottom).

Clarity. The HPHT synthetics span nearly the entire clarity scale, but most received grades in the $\mathrm{VS}_{1} / \mathrm{VS}_{2}$ range (figure 6). This is slightly lower than the clarity 


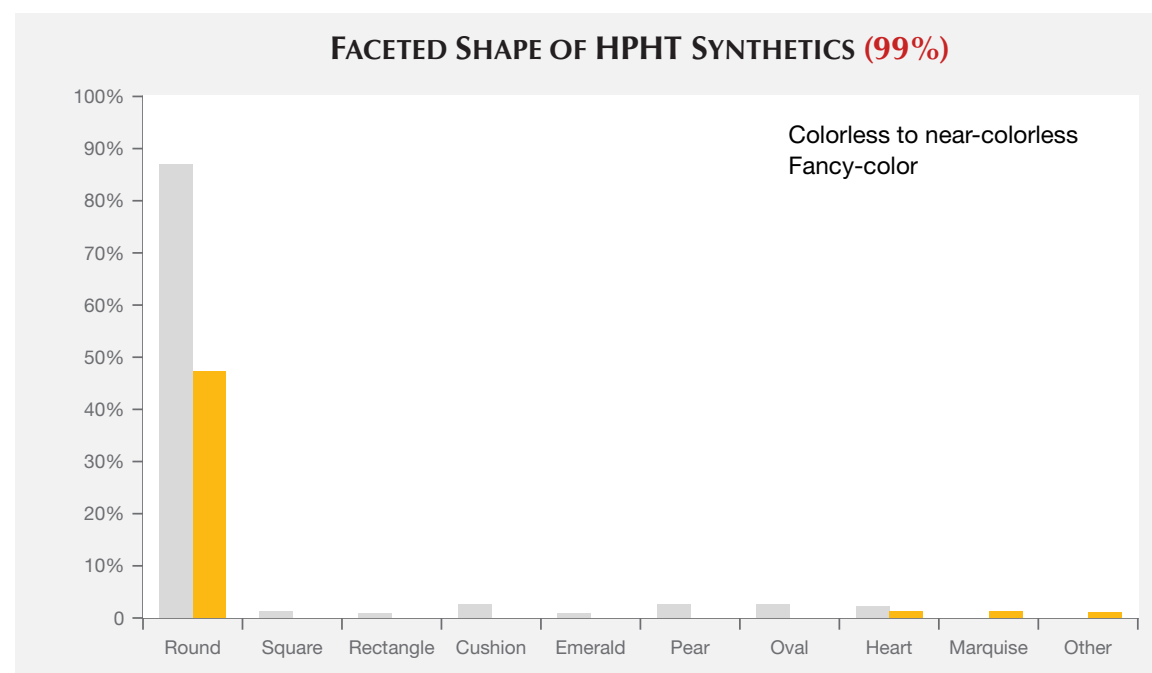

CUt GRADE FOR D-Z ROUND BRILLIANTS (6\%)

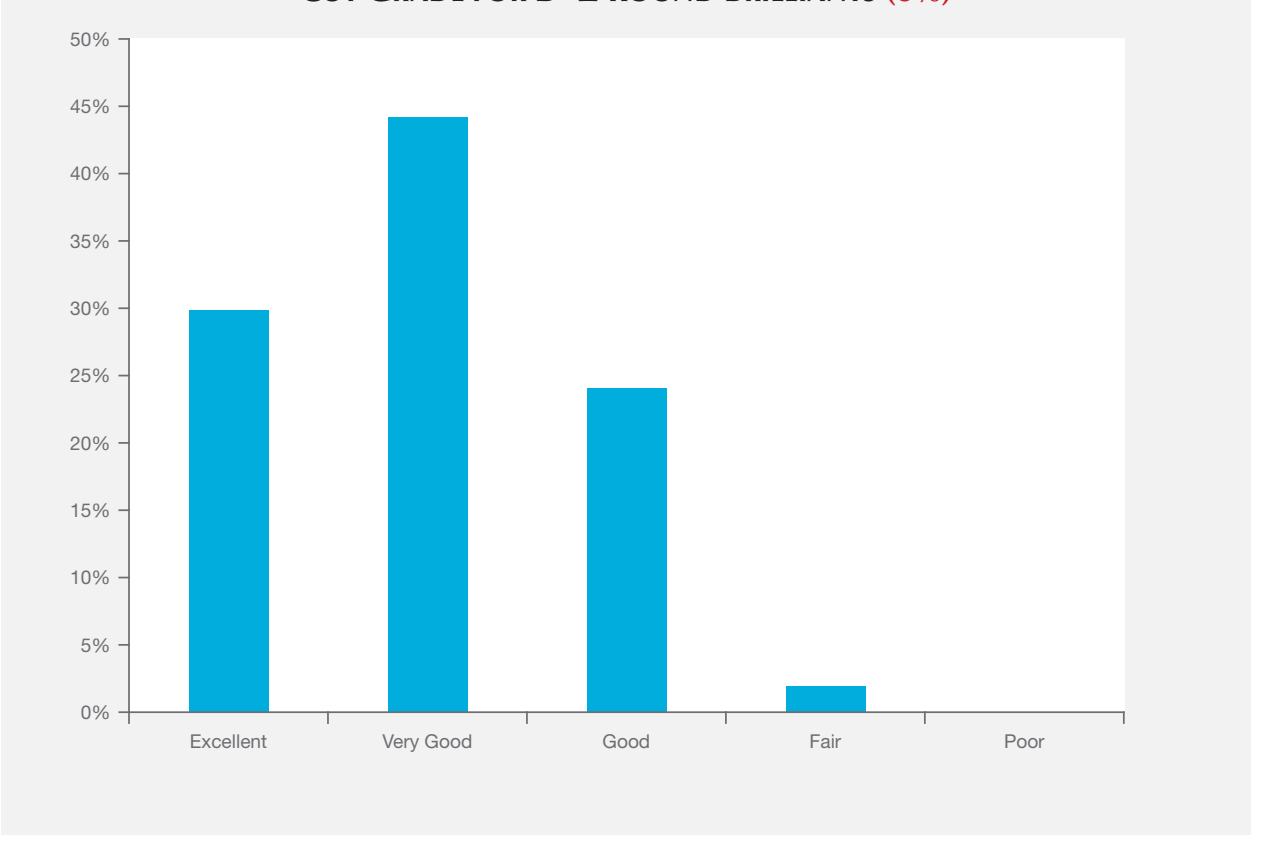

Figure 5. Top: The majority of HPHT synthetics were cut as round brilliants. Bottom: For $D-Z$ round-brilliant HPHT synthetics, a plurality had a Very Good cut grade. The percentages shown in red represent the portion of samples for which data are available. range observed for CVD synthetics, most of which were in the $\mathrm{VVS}_{2} / \mathrm{VS}_{1}$ range, and slightly higher than the $\mathrm{VS}_{2} / \mathrm{SI}_{1}$ range observed for colorless to near-colorless natural diamonds (Eaton-Magaña and Shigley, 2016). As GIA generally examines only the material that has been released by HPHT manufacturers as worthy of cutting, the samples likely represent what is available within the trade but might not account for the entire manufacturing output.

The clarity distribution is shifted toward higher grades among colorless synthetic diamonds than among fancy-color samples. This may be due to the different chemistry in the HPHT presses that create colorless material, or more likely the fact that most colorless goods date from recent years (figure 3, left) and represent improvements in the control of diamond crystallization.

Clarity grading of diamonds often involves the determination of the "grade-setting" clarity feature. This is the visual characteristic seen at $10 \times$ magnification that determines the clarity grade. For example, a diamond might have a large feather and a few sparse pinpoints. While both would be listed as inclusions, the feather would be considered the "grade setter." A number of different grade-setting clarity characteristics were found in these HPHT synthetics (figure 7).

The most common grade-setting inclusions for HPHT synthetic diamonds were identified by labora- 


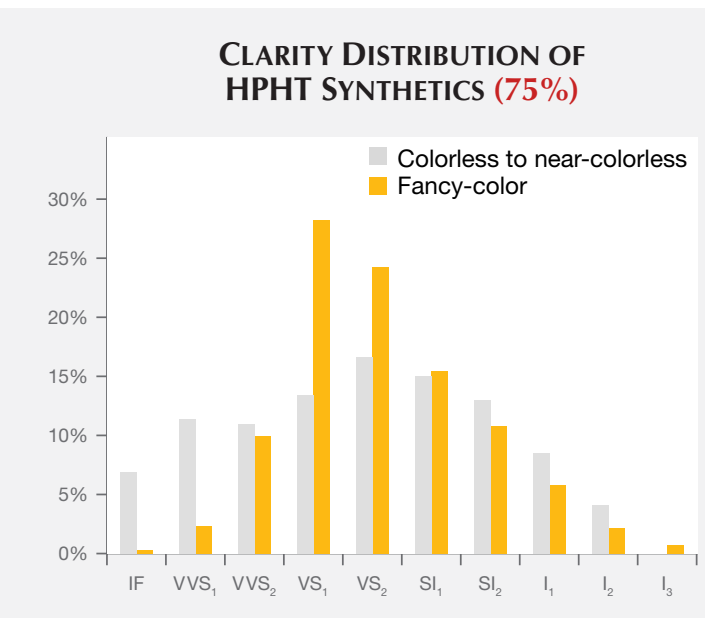

Figure 6. The clarity grade distributions are shown for colorless to near-colorless (D-I) HPHT synthetics (a plurality with $V S_{2}$ clarity) and those within the fancy color range (a plurality with $V S_{1}$ clarity). The percentage shown in red represents the portion of samples for which data are available.

tory graders as "crystals." 1 The other most common features were feathers, pinpoints, and clouds. These inclusions were mentioned in previous articles (Shigley et al., 2002, 2004; D'Haenens-Johansson et al., 2014, 2015). Many of these features also contained radial fractures surrounding larger inclusions; fractures that reached the surface are plotted as feathers.

\section{ANALYSIS OF OTHER GEMOLOGICAL PROPERTIES}

Long-Wave and Short-Wave Fluorescence. While it should not be considered conclusive evidence, the observation of ultraviolet fluorescence with a standard long-wave/short-wave UV unit has been an important and practical means of distinguishing natural diamonds from HPHT-grown synthetics. The determination is based on differences in fluorescence colors, intensities, and patterns (and in some cases the occurrence of persistent phosphorescence). If a fluorescence reaction is observed in an HPHT synthetic, the reaction to short-wave UV radiation is often stronger than to long-wave UV radiation (or the reaction to long-wave is altogether absent). For HPHT synthetics in our dataset that had both long- and short-wave fluorescence reactions, $11 \%$ showed a stronger long-wave UV reaction, $32 \%$ had equal-intensity fluorescence reactions, and $58 \%$ had a stronger short-wave reaction.

The bar graphs in figure 9 (top) illustrate the intensity of fluorescence reactions to long-wave and short-wave ultraviolet radiation from a standard gemological UV lamp. Most HPHT synthetics displayed no fluorescence reaction to long-wave UV

${ }^{1}$ Actually metal flux, as shown in figure 8, and noted as flux (or more recently as "growth remnants") on grading reports, but plotted in similar fashion as natural crystals.

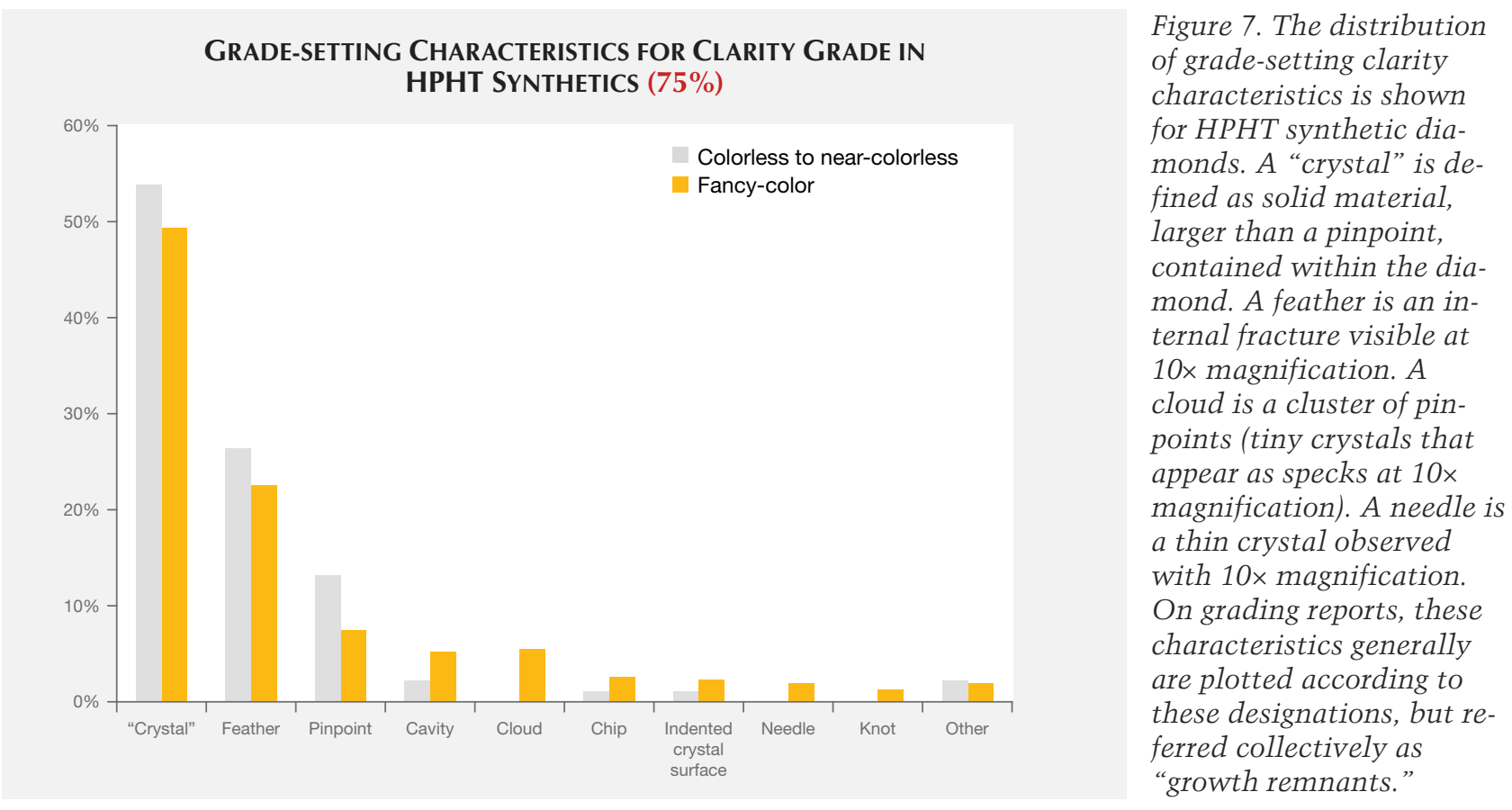



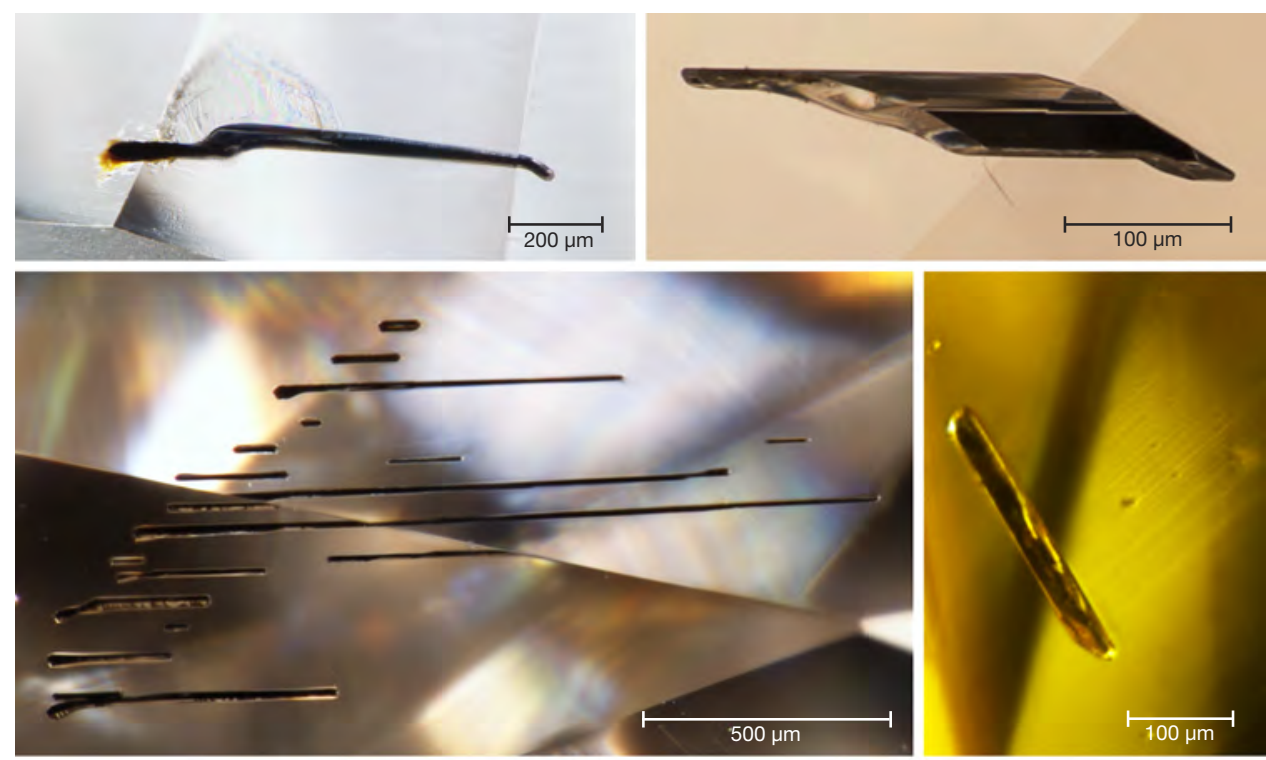

Figure 8. While some HPHT synthetic inclusions appear transparent, most appear to be pieces of dark solidified metal flux. A variety of shapes are possible, in-
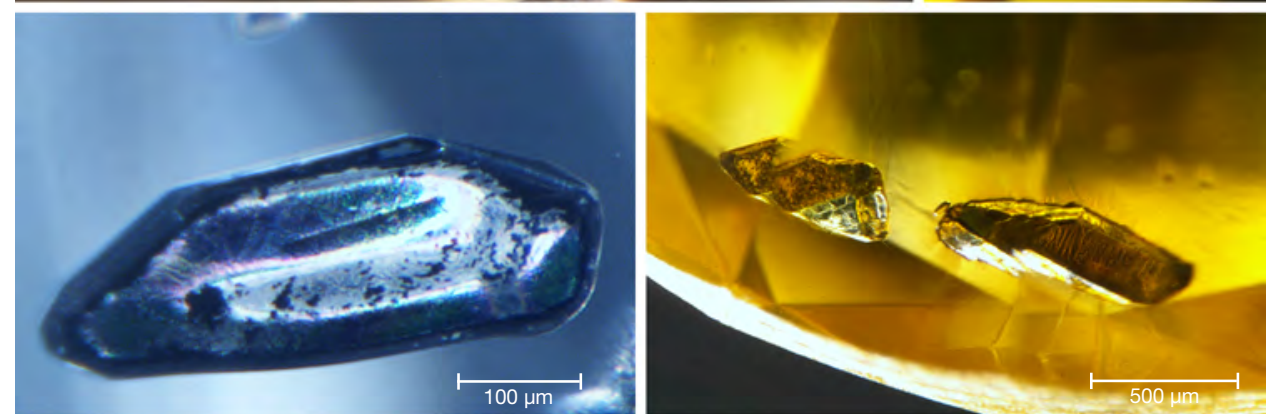
cluding thin rods and irregular shapes, and some are associated with feathers. These metallic inclusions can create a magnetic attraction. Photos by Sally Eaton-Magaña and Troy Ardon.
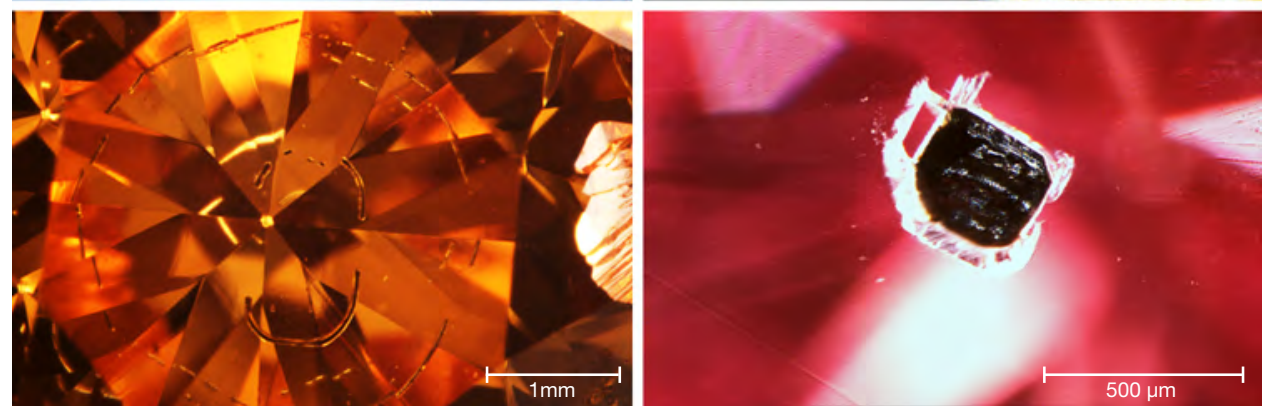

(across all colors, 74\%), while a significantly lower percentage $(38 \%)$ had no reaction to short-wave UV. While the observed fluorescence intensity was generally greater in response to short-wave rather than long-wave UV, the distribution of fluorescence color was quite similar (figure 9, bottom).

Fancy-Color Material. Among pink to red HPHT synthetics, where the color origin and the fluorescence color are due to the presence of the NV defect centers acquired during post-growth treatment, the majority showed moderate to strong fluorescence, typically with orange or red colors. Only $15 \%$ had no reaction to long-wave UV, and all pink HPHT syn- thetics exhibited an observable reaction to shortwave UV. In comparison, $16 \%$ of the natural pink diamonds had no reaction to long-wave UV, and $31 \%$ had no reaction to short-wave UV (King et al., 2002). Among those natural diamonds with observed fluorescence, the vast majority gave a blue reaction, while the remainder showed yellow or rarely orange fluorescence. Only a very small percentage $(<1 \%)$ of natural pink diamonds derive their color from $\mathrm{NV}$ centers, and it is this small percentage that showed orange rather than blue fluorescence.

Among yellow to yellow-orange material, the percentage of HPHT synthetics showing a fluorescence reaction to long-wave UV was lower than for short- 
LONG-WAVE FLUORESCENCE INTENSITY (85\%)

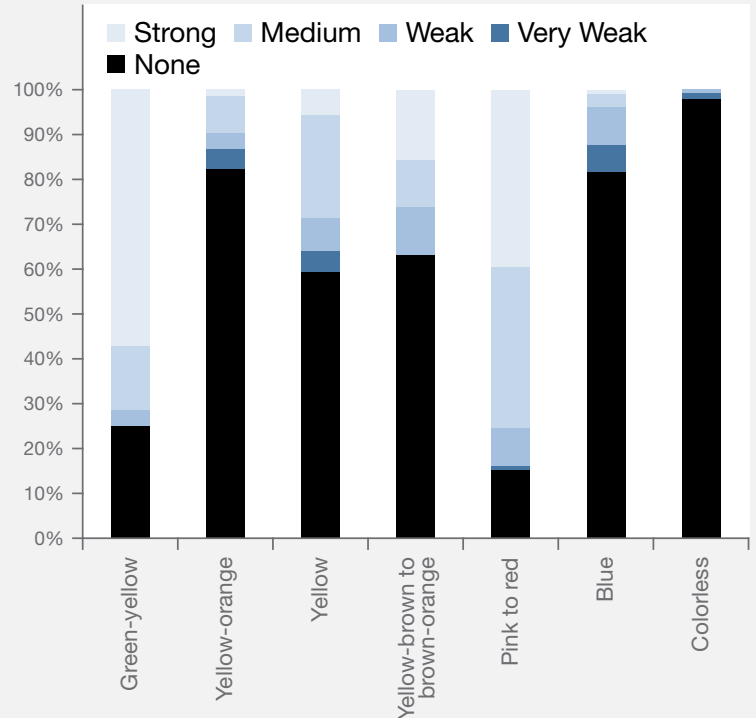

LONG-WAVE FLUORESCENCE COLOR (24\%)

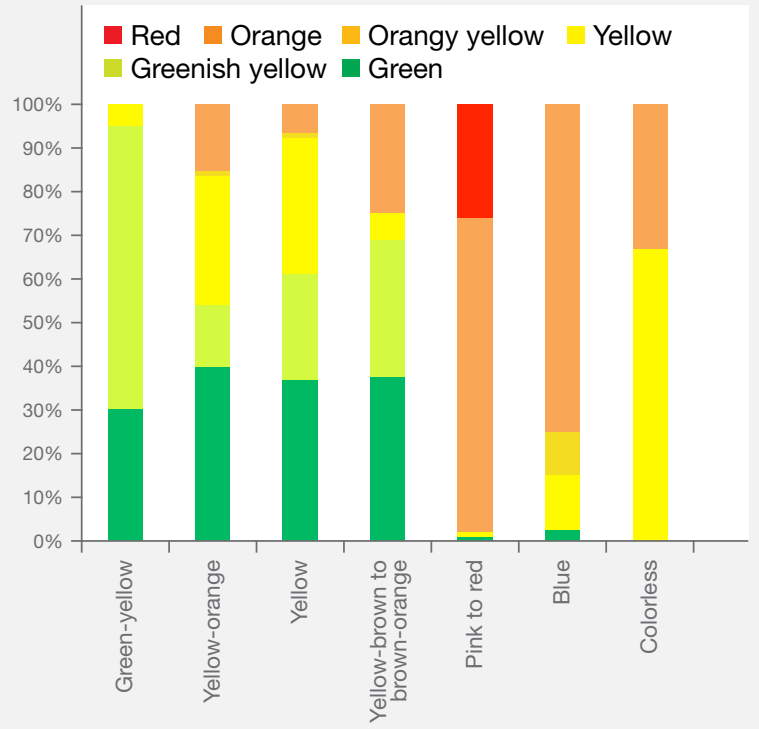

SHORT-WAVE FLUORESCENCE INTENSITY (40\%)

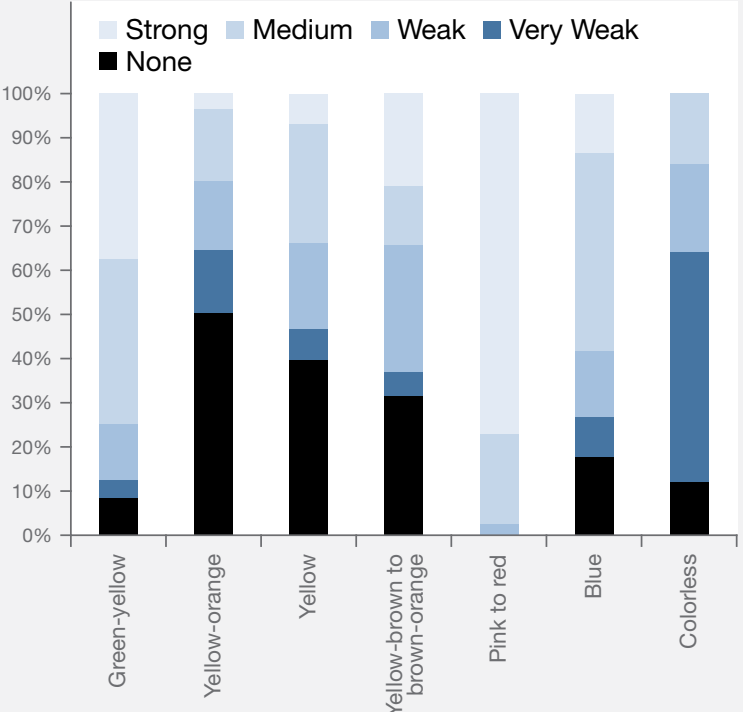

SHORT-WAVE FLUORESCENCE COLOR (25\%)

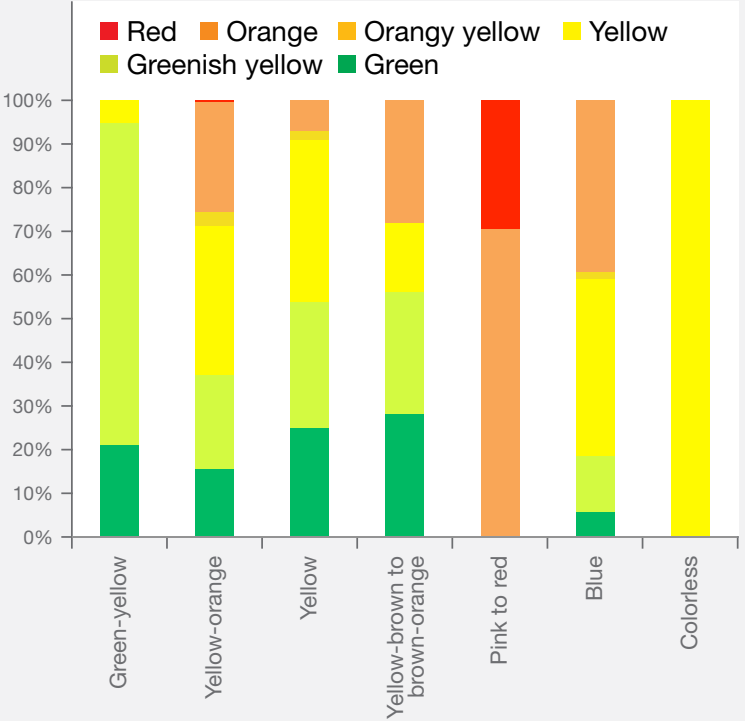

Figure 9. Fancy-color and colorless HPHT synthetics had distinctly different fluorescence reactions to long-wave and short-wave UV. Most of the HPHT synthetics showed no reaction to long-wave UV, while a majority showed an observable reaction to short-wave UV. The percentages shown in red represent the portion of samples for which data are available. The plots of fluorescence color only include those samples that had a reaction.

wave. The observed fluorescence colors were typically green to orange. This color range was distinctly different from those observed in natural diamonds, in which the most common color of long-wave fluorescence was blue (92\%; King et al., 2005).
Colorless Material. Only 2\% of colorless HPHT synthetics showed a fluorescence reaction to long-wave UV. This is a far lower percentage than observed among natural diamonds. Moses et al. (1997) reported that $35 \%$ of natural diamonds in the same color 
range had detectable long-wave fluorescence, and that $99 \%$ of the fluorescence reactions were blue due to the N3 optical defect combined with "band A" luminescence (Zaitsev, 2003). By contrast, the small percentage of HPHT synthetic diamonds with detectable long-wave fluorescence emitted orange and yellow colors.

Meanwhile, a much higher percentage (88\%) of colorless HPHT synthetics showed a fluorescence reaction to short-wave UV (figure 9). This reaction is consistent with fancy-color HPHT synthetics (Shigley et al., 2004) and prior observations of colorless HPHT synthetics (D'Haenens-Johansson et al., 2014), and opposite the expected reaction for natural diamonds (Shigley et al., 1993).

Short-Wave UV Phosphorescence. HPHT synthetics in the blue and colorless color ranges often show observable light blue phosphorescence (e.g., D'Haenens-Johansson et al., 2014, 2015) due to boron impurities (Watanabe et al., 1997). Treated and natural blue type IIb diamonds often showed blue phosphorescence as well, though typically weaker (natural type IIb diamonds can also show red phosphorescence; Eaton-Magaña and Lu, 2011). Among the other HPHT synthetic diamond colors, the majority did not exhibit observable phosphorescence. For example, only one of the yellow-orange samples showed phosphorescence /weak orange).

DiamondView Imaging. For the past two decades, the DiamondView fluorescence imaging instrument has been an important diamond identification tool for major gemological laboratories. The design of the sample holder allows diamonds to be positioned and examined in various orientations, and the fluorescence reactions can be observed in real time. The very short wavelength $(\sim 225 \mathrm{~nm})$ and high intensity of the UV excitation source creates fluorescence just beneath facet surfaces, producing a distinct reaction. Although most HPHT synthetics show no reaction to a standard long-wave UV light source and many are inert to short-wave UV, all diamonds-including all HPHT synthetics-show some observable reaction to the high-intensity, high-energy UV source.

Differences in UV fluorescence colors and patterns provide the basis for DiamondView analysis (Welbourn et al., 1996). Because of their unique growth environment, HPHT synthetics exhibit distinctive fluorescence reactions under the DiamondView.
Growth Features. The growth features of HPHT synthetics are created largely by the prevailing growth chemistry and process conditions that have existed for several decades. In order to lower the temperature and pressure necessary for HPHT growth, as well as the associated expense, manufacturers use a metal catalyst (see "HPHT Synthetic Diamond Growth" above). At these lower temperatures, octahedral growth (as seen in natural diamond crystals) is not observed (Welbourn et al., 1996). Instead, cuboctahedral growth predominates (at even lower temperatures, cube growth would occur). The vast majority of distinctive growth features seen in HPHT synthetics are due to this cuboctahedral arrangement of internal growth sectors, as well as accompanying variations that can occur with different metal catalysts (Welbourn et al., 1996).

The two as-grown HPHT synthetic crystals in figure 10 demonstrate the characteristic external crystal morphology. Their corresponding DiamondView fluorescence images show the different fluorescence reactions along these growth faces. The impurities and defects created in HPHT synthetics can vary greatly depending on the growth face, and these variations

Figure 10. As-grown HPHT crystals show a cuboctahedral growth morphology that is quite distinct from both natural and CVD-grown diamonds. These higher-order growth faces, such as (113), incorporate defects at different concentrations, leading to distinctive fluorescence colors and patterning that arise from the arrangement of internal growth sectors. The distinctive fluorescence reactions in the DiamondView images on the right remain after polishing, proof of HPHT growth. Photos and images by Sally Eaton-Magaña (top row) and GIA staff (bottom row).
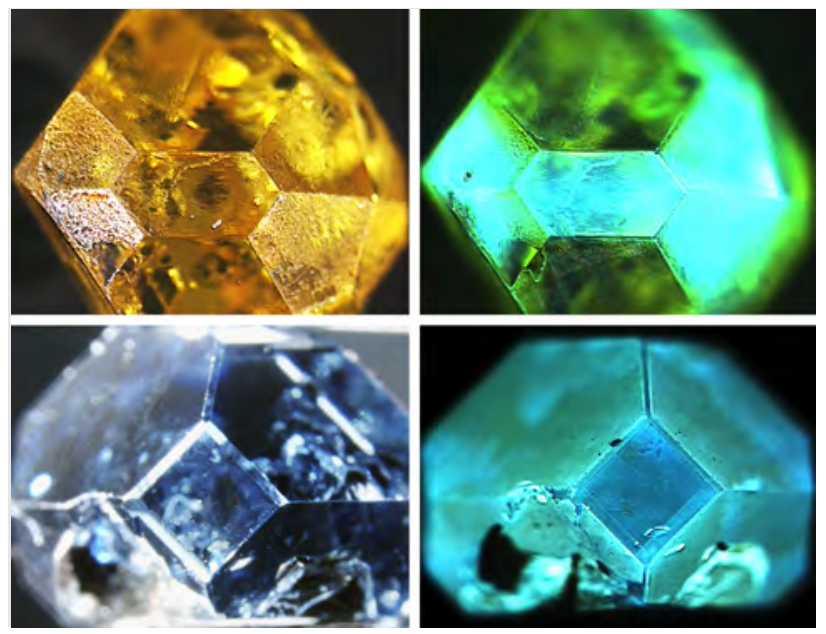


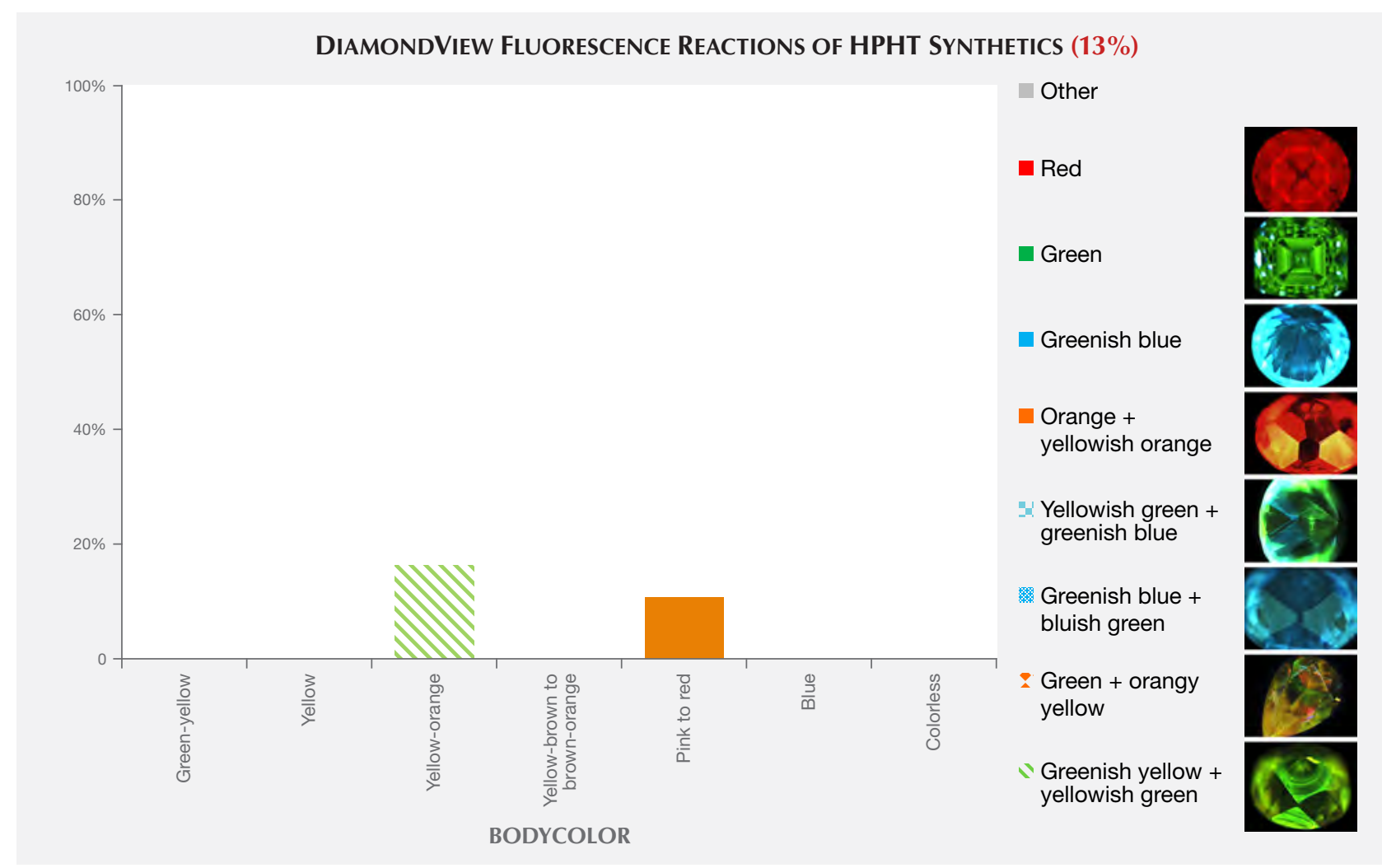

Figure 11. Due to the variety of growth conditions and optical defects among the various colors of HPHT synthetic diamonds - grown with low accidental amounts or deliberately high amounts of nitrogen and/or boronthese samples exhibit a wide variety of DiamondView fluorescence reactions. The distinct internal growth structure seen with the DiamondView is generally diagnostic of HPHT synthesis. Most colorless HPHT synthetics have low but detectable amounts of boron, and DiamondView imaging shows similar colors and phosphorescence properties as blue HPHT synthetics. The percentage shown in red represents the portion of samples for which data are available.

are revealed by the different fluorescence colors. Once an HPHT synthetic is polished, the as-grown morphology can no longer be easily observed unless there is noticeable color zoning. However, the differences in defect chemistry within these growth faces are preserved even in colorless material, with the fluorescence reaction and pattern revealed quite clearly by DiamondView imaging.

Fluorescence Color. With the DiamondView, a wide variety of fluorescence colors can be observed in HPHT synthetics. HPHT synthetics often exhibit more than one fluorescence color (e.g., green and greenish blue in figure 10, top); examples of the fluorescence colors are shown in figure 11.

Fancy-color diamonds generally show a contrast in fluorescence color between the various growth planes. Often the planes reveal two distinct fluorescence colors, or a combination of regions with and without fluorescence. The green fluorescence is as- cribed to $\mathrm{H} 3$ defects, while the orange to red fluorescence originates from $\mathrm{NV}$ centers. The origins of the other fluorescence colors are less understood by scientists. A comparison of these fluorescence colors against other known spectral features did not indicate any compelling correlations.

With colorless HPHT synthetics, the contrast in fluorescence color between growth sectors is much more subtle (D'Haenens-Johansson et al., 2014) and can be difficult for a gemologist to detect even while rotating the sample in the DiamondView. For colorless diamonds in particular, the gemologist must be especially vigilant when looking for growth features in the DiamondView. This reduction in color contrast is due to fewer defects and color-causing impurities in colorless as compared to fancy-color HPHT synthetics. Therefore, the concentration differences of defects between the growth sectors that create the fluorescence will not be as apparent. 

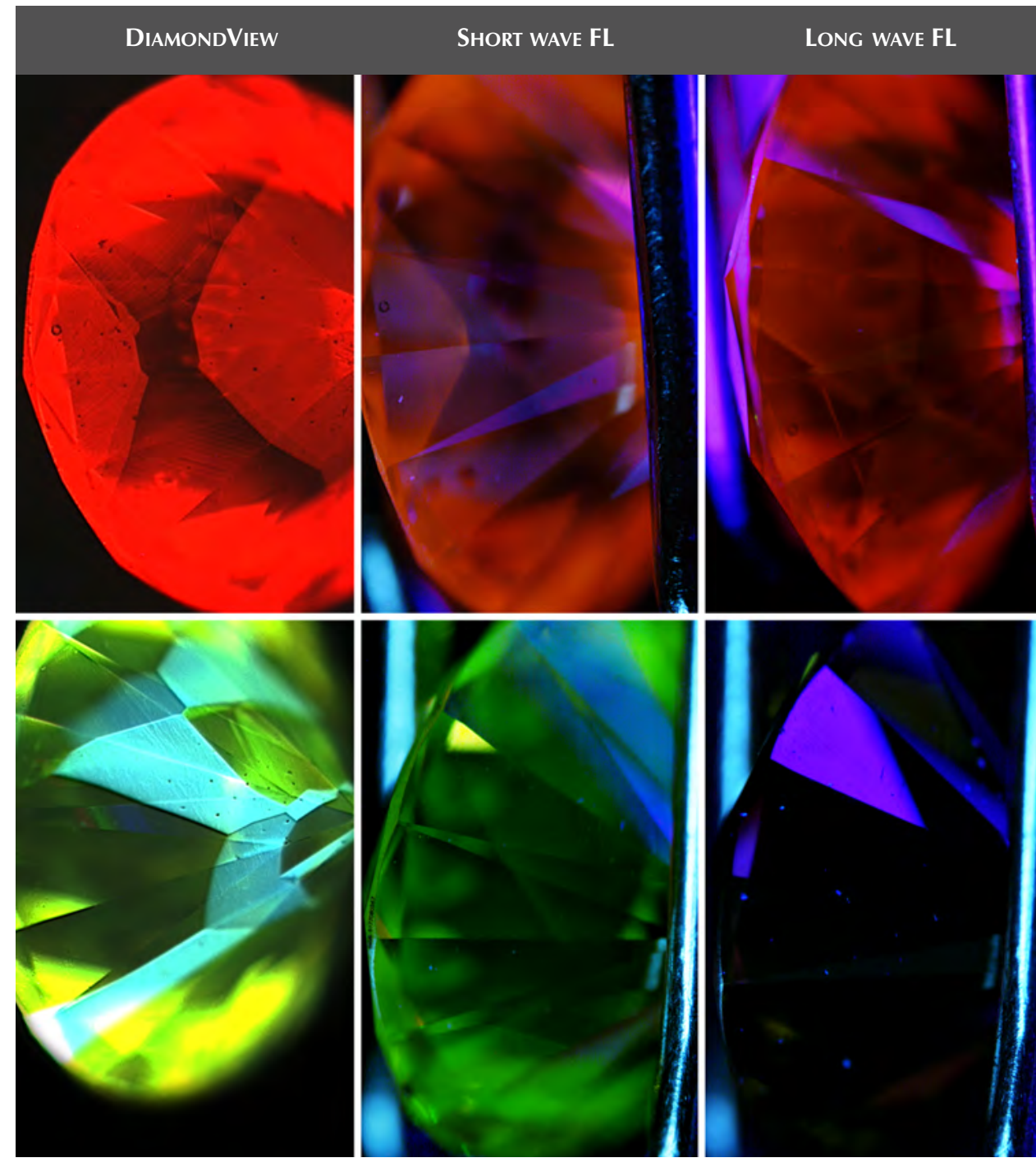

Figure 12. These images show the differences in detail and color contrast when two HPHT synthetics are illuminated by the DiamondView instrument (deep ultraviolet illumination at $225 \mathrm{~nm}$ ), short-wave UV (254 nm), and long-wave UV (365 $n m)$. The top series, of $a$ 0.32 ct Fancy Deep pink, shows the ideal case in which HPHT synthetic features are observable with short-wave UV. The bottom series, of a $0.59 \mathrm{ct}$ Fancy Vivid orangy yellow, represents a far more common observation. Besides a difference in fluorescence ( $F L$ ) intensity between short-wave and long-wave UV, there is no evidence of HPHT growth patterns. For the shortwave and long-wave UV images, purple reflections of the UV source are observed in addition to the diamonds' fluorescence.
DiamondView Reaction Compared with ShortWave and Long-Wave UV Fluorescence. Figure 12 shows the fluorescence reaction observed for two fancy-color HPHT synthetics. The series in figure 12 (top) clearly indicates the hourglass growth zoning indicative of HPHT synthetic growth when illuminated by the deep ultraviolet $(225 \mathrm{~nm})$ illumination of the DiamondView. Using short-wave UV, the hourglass pattern is still visible, but not as distinct. While the HPHT synthetic exhibits some reaction to long-wave UV, there is no observable pattern.

Far more common among HPHT synthetics is the sample in figure 12 (bottom), in which the DiamondView shows a reaction that is distinctive of HPHT synthetics while the short-wave and long-wave UV fluorescence pattern are not at all diagnostic of HPHT growth. The superior detail and pattern contrast of DiamondView imaging has made the instru- ment indispensable in gemological laboratories, as the quality of data cannot be matched using shortwave or long-wave UV lamps. Published reports on synthetic diamonds often include fluorescence reactions observed with the DiamondView, so the gemologist should understand that such reactions are less intense and less obvious using a standard longwave/short-wave UV lamp.

\section{SPECTROSCOPIC PROPERTIES}

While HPHT samples have more diagnostic gemological properties than CVD samples (such as color zoning, lack of strain, and magnetism; see box A), the absence of these properties does not conclusively identify a diamond as natural. Spectroscopic techniques are essential to verify the growth origin of all diamonds. Among the samples identified as potential HPHT synthetics, a combination of features in 
Fourier-transform infrared absorption (FTIR), visible/near-infrared (Vis-NIR) absorption, and photoluminescence (PL) spectroscopy will confirm the determination. Therefore, positive detection of HPHT synthetics is best accomplished by a major gemological laboratory that maintains a database of known natural, treated, and synthetic diamonds and sees a sufficient quantity of goods to spot emerging trends.

Infrared (IR) Absorption Spectroscopy. In colorless diamonds, IR absorption spectroscopy is most useful in separating type Ia, which represents the vast majority of natural diamonds, from diamonds that do not contain aggregated nitrogen (Breeding and Shigley, 2009). This is the basis of GIA's DiamondCheck instrument. This distinction is important in colorless diamonds, as only those without detectable aggregated nitrogen are identified as potentially treated or synthetic.

Among fancy-color HPHT synthetics, either with as-grown yellow-to-green or treated pink colors, IR absorption spectra display the $1344 \mathrm{~cm}^{-1}$ peak. This feature indicates the presence of single substitutional nitrogen (i.e., type Ib diamond) and shows that the diamond is potentially quite young in geologic terms. While some natural diamonds can also be type $\mathrm{Ib}$, this peak is a good indicator of potential HPHT synthetic origin, as young diamonds contain only isolated nitrogen. In natural stones, over the millions of years that diamonds reside at higher temperatures in the earth, these isolated nitrogen atoms randomly migrate within the diamond lattice (figure 13) and inevitably find another nitrogen defect to form what are called nitrogen aggregates. The A aggregate (a pair of substitutional nitrogen atoms in adjacent lattice sites) can also combine to form the B aggregate (four nitrogen atoms surrounding a vacant atom position in the lattice). While this aggregation process can be duplicated to some extent in the laboratory using high temperature instead of millions of years, there are differences. For example, the isolated nitrogen indicated by the $1344 \mathrm{~cm}^{-1}$ peak will never be completely eliminated using high-temperature treatment, and this feature will still be detected by IR spectroscopy (Dobrinets et al., 2013). Among natural diamonds, the aggregation process over long periods of geologic time removes nearly all isolated nitrogen so that the distinct infrared spectral feature cannot be detected in most natural diamonds.

Many of our HPHT synthetic samples showed, based on their infrared spectra, a pure type Ib charac-

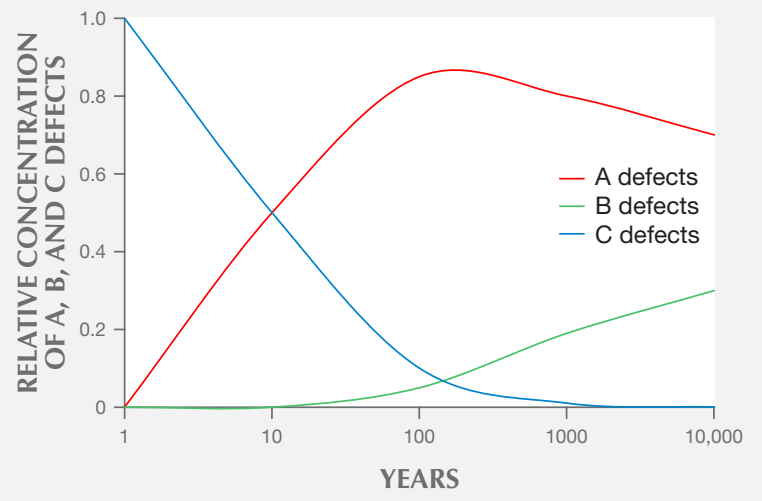

Figure 13. Isolated nitrogen (C defects) decrease as they are converted into aggregated nitrogen $(A$ and $B$ centers) while at temperatures of $800-1400^{\circ} \mathrm{C}$ within the earth. After Dobrinets et al. (2013), figure 9.2, $p$. 235. In contrast, young diamonds such as HPHT synthetics have very low nitrogen aggregation.

ter (i.e., only isolated nitrogen), while others exhibited a combination of type IaA /due to heating, which created some aggregated nitrogen) and type $\mathrm{Ib}$ (figure 14). Whether the manufacturers are creating A aggregates by maintaining the chamber at high temperature during the growth process or by subjecting the diamonds to post-growth treatment to enhance nitrogen aggregation is not entirely clear.

Blue HPHT synthetics (along with a majority of colorless HPHT samples) were type IIb, indicating either intentional doping or accidental contamination with boron in the growth chamber. Figure 15 shows the distribution of diamond types among HPHT synthetics based on bodycolor. Those with yellow color were predominantly type Ib or a combination of type Ib and type IaA. The blue synthetics were exclusively type IIb. Colorless HPHT synthetics were type IIa or, more commonly, type IIb (where the amount of boron was insufficient to produce any blue coloration). The post-growth treated pinks were type IIa or type $\mathrm{Ib}$, but with very low nitrogen concentrations.

As mentioned previously when discussing color differences in the DiamondView imaging and with color zoning, defect incorporation among the various internal growth sectors of HPHT synthetics can be quite variable. Therefore, boron and isolated nitrogen concentrations are not uniformly distributed throughout. IR absorption spectroscopy on faceted stones generally samples most of the volume of the crystal or cut stone, and the resulting spectra reflect 


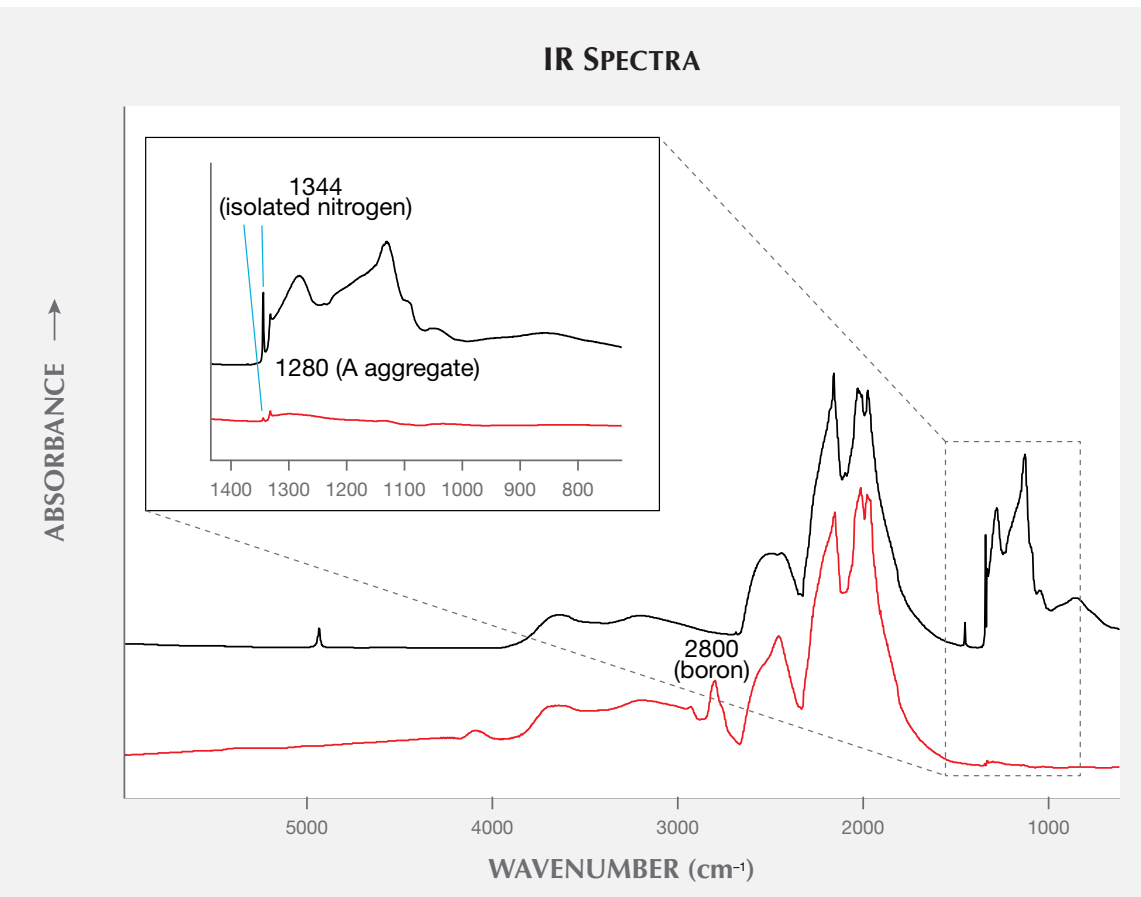

Figure 14. Infrared spectra for two HPHT synthetics. The black trace is the IR spectrum of an HPHT synthetic with type IaA $\left(1280 \mathrm{~cm}^{-1}\right)+$ type Ib components (1344 $\left.\mathrm{cm}^{-1}\right)$. It is a 0.34 ct Fancy brown-red with 220 ppma of isolated nitrogen and 60 ppma of nitrogen A aggregates. The red trace is an $I R$ spectrum of a Fancy light greenish yellow HPHT synthetic with type IIb (95 ppb uncompensated boron; 2800 $\left.\mathrm{cm}^{-1}\right)+$ type Ib (2 ppm isolated nitrogen; $1344 \mathrm{~cm}^{-1}$ ) components. These spectra show the range in diamond types and nitrogen concentration in HPHT synthetics. The absorption feature between 2700 and $1550 \mathrm{~cm}^{-1}$ is principally intrinsic to diamond.

an average concentration across the bulk of the diamond. With that caveat in mind, the electrically uncompensated boron concentration detected by IR absorption $\left(\mathrm{B}^{0}\right)$ and the isolated nitrogen concentration (Ns) were calculated from 160 randomly chosen type IIb HPHT synthetics and 180 type Ib (or type IaA
+ type Ib) HPHT synthetics. The concentration for $\mathrm{B}^{0}$ was calculated from a method after Collins and Williams (1971) and Fisher et al. (2009), or alternatively Collins (2010). Ns was calculated from a procedure described by Kiflawi (1994). These concentration values are shown in figure 16.

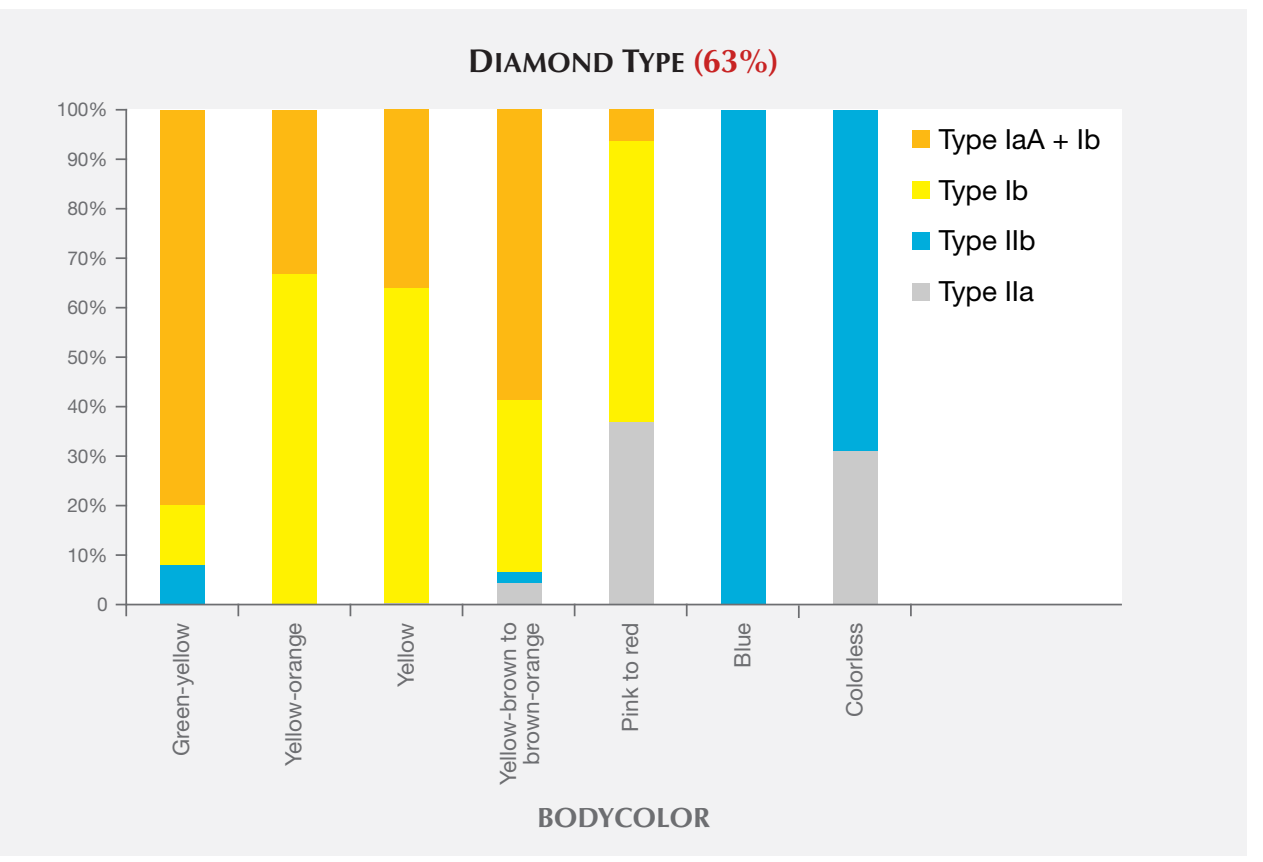

Figure 15. HPHT synthetics span four diamond type combinations: type IIa, type $I I b$, type Ib, and mixed type $I a A+I b$. Those with yellow coloration were predominantly type Ib or mixed type $I a A+I b$. Colorless diamonds were either type IIa or had a comparatively low boron concentration and were type IIb. All blue diamonds were type IIb. Pink to red synthetics get their color from post-growth treatment; while most were type $I b$, the nitrogen concentration was low (see figure 16, right). The percentage shown in red represents the portion of samples for which data were used. 

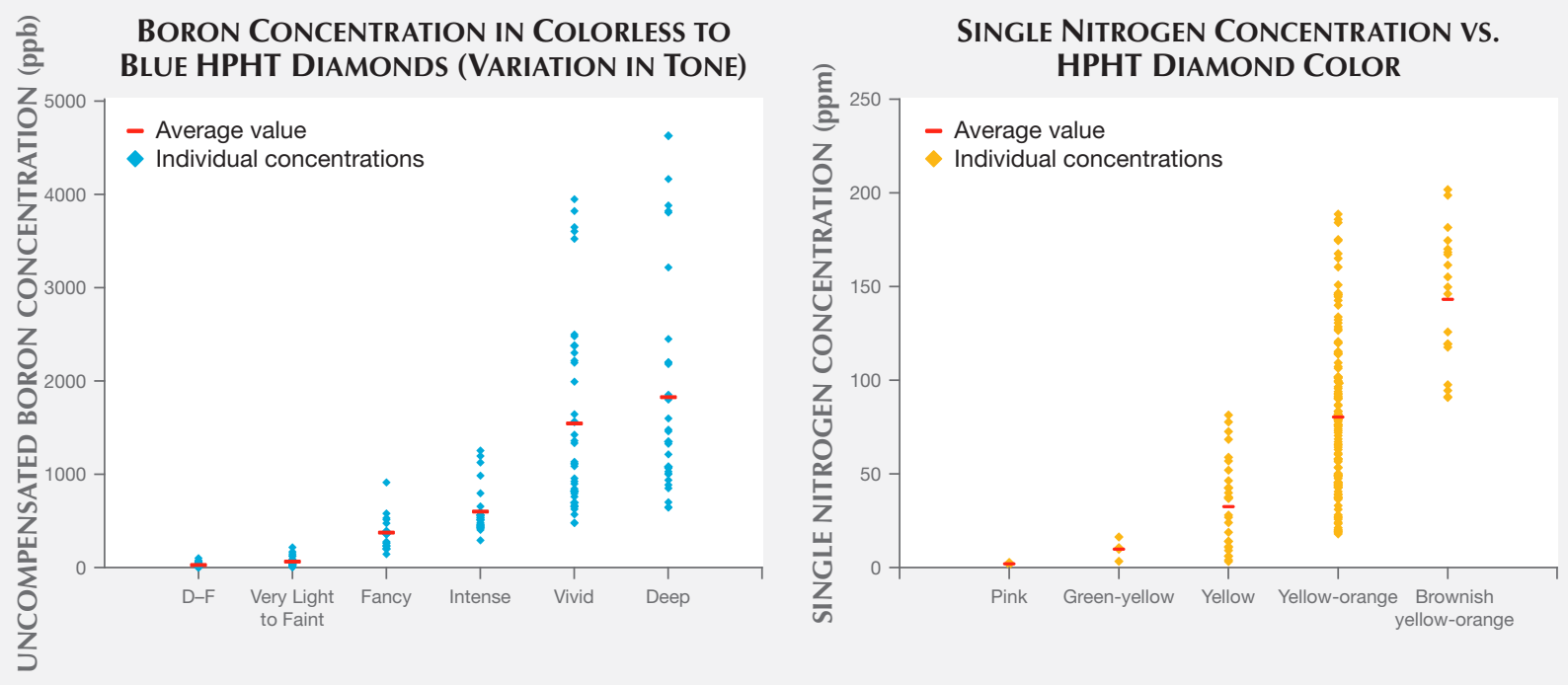

Figure 16. Absolute concentrations for uncompensated boron concentration in type IIb synthetics (left; provided as ppb, parts per billion) and isolated nitrogen concentration in type Ib synthetics (right; provided as ppm, parts per million) were calculated. Increasing the boron concentration in type IIb synthetics predictably increased the depth of color, with Fancy Deep blue synthetics having the highest values. Among the type Ib diamonds, the depth of yellow to orange color increased with nitrogen concentration.

The measured boron concentrations spanned a wide range of values. Figure 16 (left) shows the calculated values for the uncompensated boron concentration, $\mathrm{B}^{0}$, in colorless HPHT synthetics and in fancy-color blues as the tone increases left to right, from Very Light up to Fancy Deep. In several cases for the Fancy Vivid and Fancy Deep samples, the boronrelated feature at $2800 \mathrm{~cm}^{-1}$ in the IR spectrum was saturated (i.e., the peak height was beyond the vertical scale of the graph) and could not be calculated with this method and an alternate correlation was performed using the feature at $1290 \mathrm{~cm}^{-1}$ (Collins, 2010). The D-F colorless HPHT synthetics had the lowest boron concentrations, with the Very Light to Fancy Light blue samples encompassing a slightly higher range. The highest measured concentration was 4627 $\mathrm{ppb}$, which is comparable to a value calculated for a natural type $\mathrm{IIb}$ diamond with very high boron (Johnson and Wang, 2015).

Figure 16 (right) shows the spread of values for the isolated nitrogen concentration for type Ib HPHT synthetics of various colors. The pinks and green-yellows had the lowest nitrogen concentrations, followed by yellow, yellow-orange, and brownish yellow-orange samples. In the early years of production in the 1980s and 1990s, most HPHT synthetics were yellow-orange, likely due to a high nitrogen concentration, which growers were not able to reduce or eliminate as effectively at the time. As the incorporation of isolated nitrogen became better controlled over the years, the orange coloration was reduced. Therefore, the manufacturers could more consistently produce HPHT synthetics with lower quantities of nitrogen, allowing a wider variety of colors and the production of more saleable stones. For example, the pink synthetics look more appealing when starting with an HPHT synthetic that has low, rather than high, concentrations of nitrogen (Shigley et al., 2004).

Vis-NIR Spectroscopy. For many of the fancy-color HPHT synthetics, the broadband absorptions observed in the visible/near-infrared spectra resemble those of their natural diamond counterparts. This similarity illustrates the need for multiple spectroscopic techniques and gemological observations to confirm an identification result. Spectra for blue and most yellow to yellow-orange HPHT samples are indistinguishable from natural diamond spectra. The Vis-NIR spectra of pink to red diamonds indicate the treatment history of irradiation and annealing that created the pink color rather than the synthetic origin (figure 17). For most colors of HPHT synthetics, a small percentage of the samples showed spectral peaks associated with the metal catalyst, mostly nickel (figure 17; Zaitsev, 2003).

Yellow-orange HPHT synthetics comprise a majority of the samples examined by GIA to date. These 
VIS-NIR ABSORPTION SPECTRUM FEATURES IN HPHT SYNTHETICS (54\%)

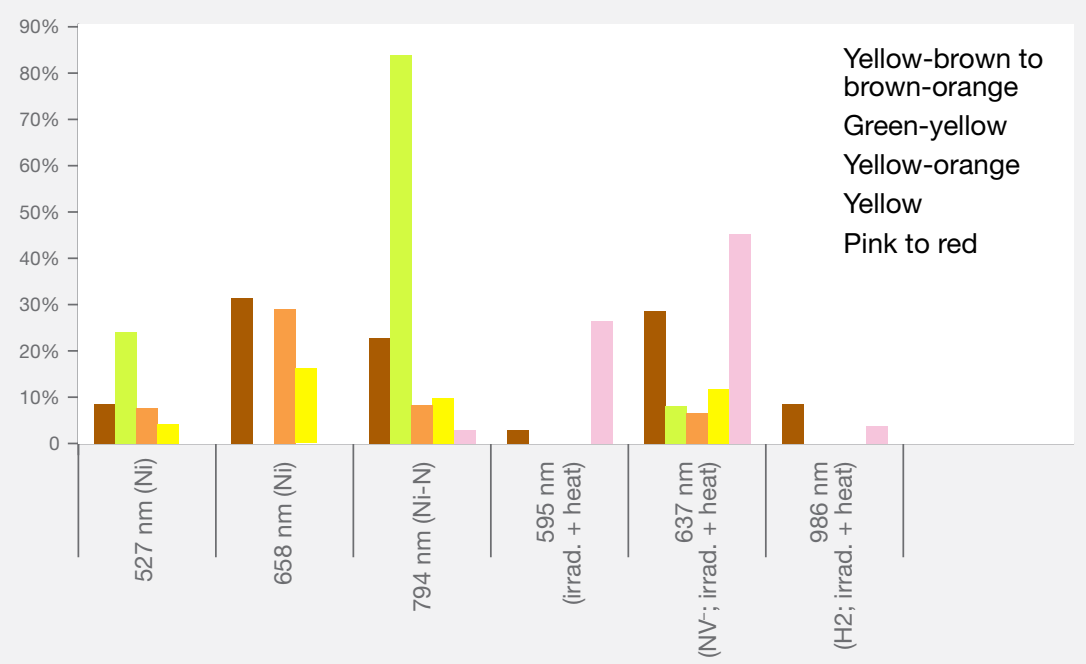

Figure 17. The major features seen in the Vis-NIR absorption spectra are shown for HPHT synthetics, grouped by color. These peaks were ascribed to nickel incorporation from the catalyst, nitrogen-related defects due to a high concentration of nitrogen, or postgrowth treatment that increased these specific nitrogen defect complexes (Zaitsev, 2003). The percentage value shown in red represents the portion of samples for which data were used. include samples with color grades in order of increasing orange contribution: orangy yellow, orange-yellow, yellow-orange, and yellowish orange. To examine whether the differences in color grade between these "yellow-orange" HPHT synthetics and the pure yellow samples could be detected in the VisNIR spectra, we plotted 25 randomly selected yellow HPHT synthetics and 25 yellowish orange HPHT synthetics (figure 18). In these spectra, there was little difference in the absorption between the yellow and the yellowish orange synthetics at wavelengths greater than $600 \mathrm{~nm}$. Below $600 \mathrm{~nm}$, however, the onset of increased absorption occurs at longer wavelengths in yellowish orange synthetics. In other words, the portion of the graph showing increased absorption is shifted toward longer wavelength values for the yellowish orange samples, pushing the transmission window closer to the orange region. This absorption increase at longer wavelengths among the yellowish orange samples is due to greater nitrogen absorption within the UV range and consistent with IR calculations for the isolated nitrogen shown in figure 16 (up to $100 \mathrm{ppm} \mathrm{N}$ in yellow samples, and up to $200 \mathrm{ppm} \mathrm{N}$ in yellow-orange samples). As the HPHT synthetic process improved and less nitrogen was incorporated, the nitrogen-related absorption decreased as well.

Photoluminescence (PL) Spectroscopy. PL spectroscopy is a very sensitive analytical technique that can detect light emission from optical defects at much lower concentrations than absorption spectroscopy. The PL method, where spectral features are excited by incident laser light of specific wavelengths, is therefore capable of detecting optical centers in diamond when Vis-NIR and IR absorption cannot. PL spectroscopy is a vital technique for gemological laboratories in determining diamond origin and color origin, and HPHT synthetics are no exception.

PL spectra features for HPHT synthetics were predominantly nitrogen $\left(\mathrm{H} 3, \mathrm{NV}^{0}, \mathrm{NV}^{-}\right.$, and $\left.\mathrm{H} 2\right)$ and nickel defect-related $(658,696,794$, and $883 / 884 \mathrm{~nm}$; Zaitsev, 2003; figure 19). While nickel was present in

Figure 18. The Vis-NIR spectra of 25 yellow and 25 yellowish orange synthetics are compared to show a shift in the nitrogen-related absorption edge at 520 $\mathrm{nm}$, the cause of their color differences. This shift to higher wavelengths is caused by a higher isolated nitrogen concentration in the yellowish orange HPHT synthetics.

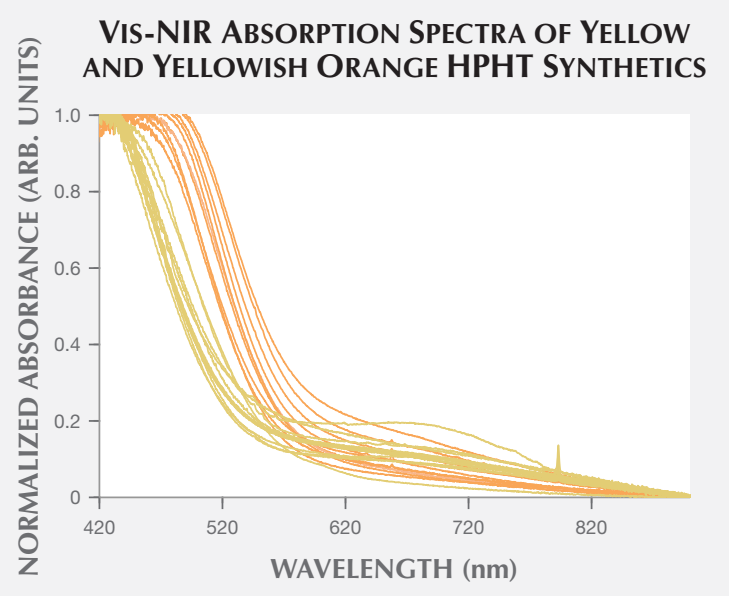




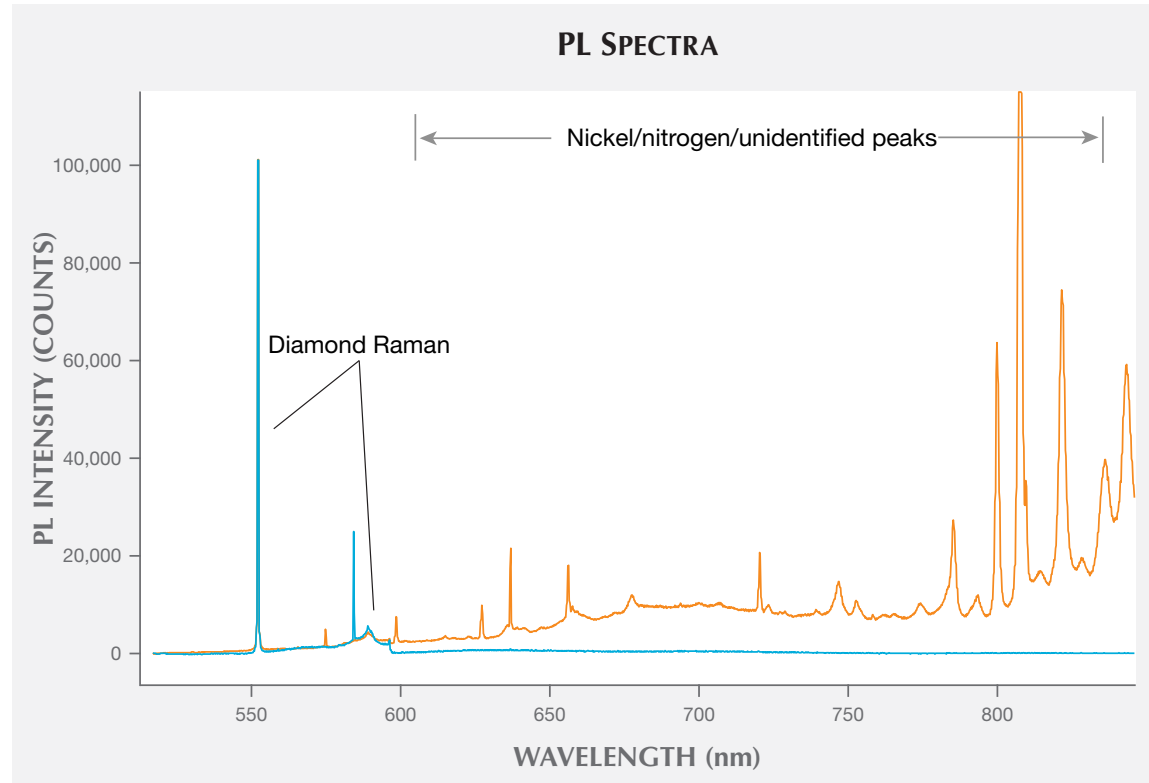

Figure 19. These PL spectra were recorded using $514 \mathrm{~nm}$ excitation with the first-order Raman intensities in each spectrum scaled to be equal. The blue trace is for a 0.71 ct type IIb Fancy blue HPHT synthetic; it did not contain any peaks besides intrinsic diamond-related peaks in the PL spectra using 488, 514, and $830 \mathrm{~nm}$ excitation. The orange trace represents a 0.45 ct Fancy Deep brownish orangy yellow diamond showing a variety of peaks, including nitrogen- and nickel-related defects.

a notable percentage of the synthetics-the $794 \mathrm{~nm}$ peak was detected in $83 \%$ of the tested yellow-orange HPHT synthetics, while the $883 / 884$ nm doublet was present in $30 \%$ of the colorless and $8 \%$ of the blues- it was not found in all synthetics and is not a reliable indicator (figure 20). It is occasionally observed in the luminescence spectra of natural diamonds (Lang et al., 2004; Eaton-Magaña et al., 2016). Not surprisingly, the

Figure 20. The major features seen in the PL spectra of HPHT synthetics, grouped by color. These peaks were either ascribed to nickel incorporation due to the catalyst, nitrogen-related defects due to a high concentration of nitrogen, or post-growth treatment that increased these specific nitrogen complexes. A sizeable portion of the blue and colorless synthetics were featureless, besides their intrinsic diamond peaks, using 488, 514, or $830 \mathrm{~nm}$ laser excitation. The percentage value shown in red represents the portion of samples for which data were used.

\section{PL FEATURES IN HPHT SyNTHETICS By COLOR (12\%)}

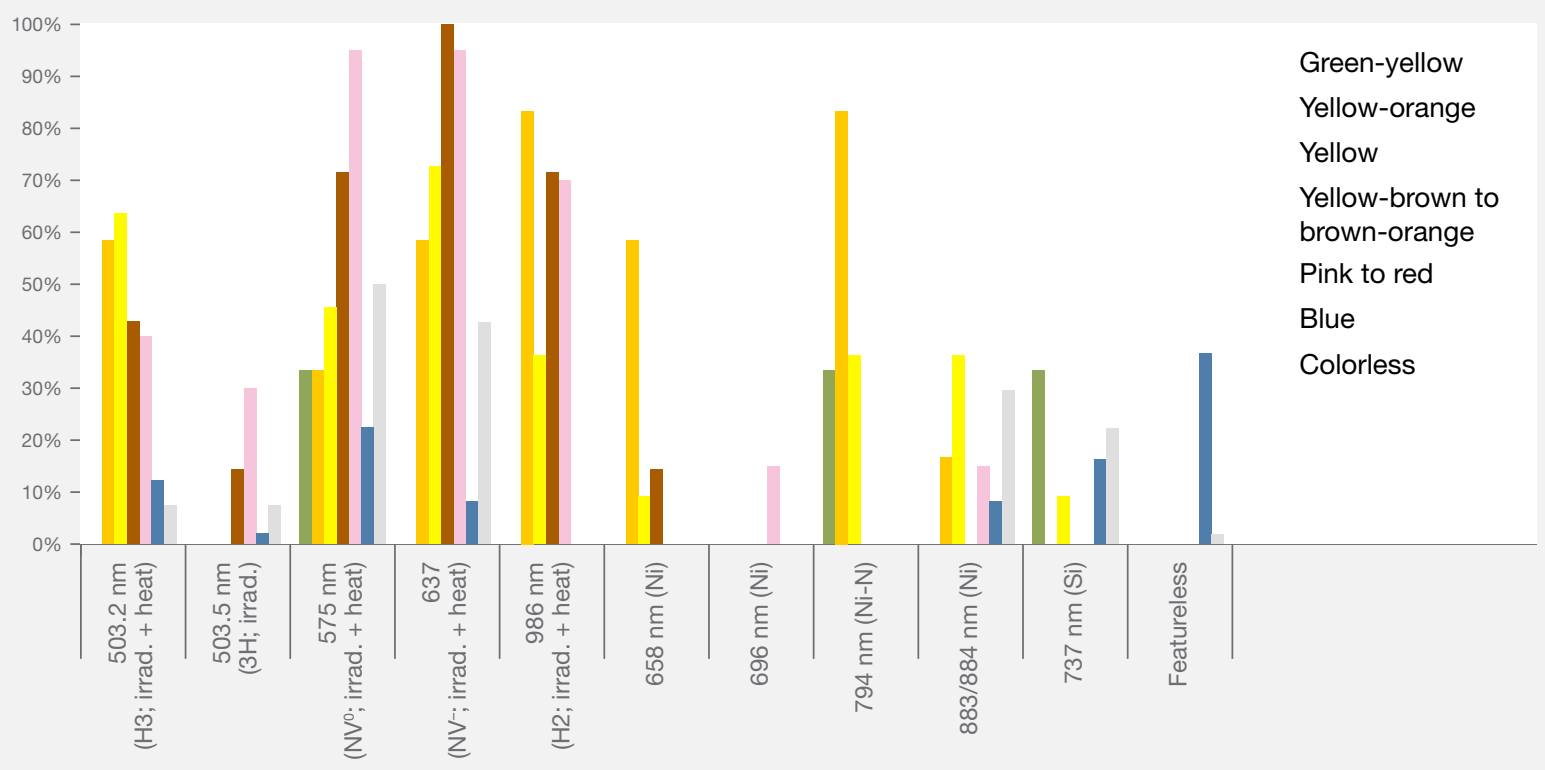




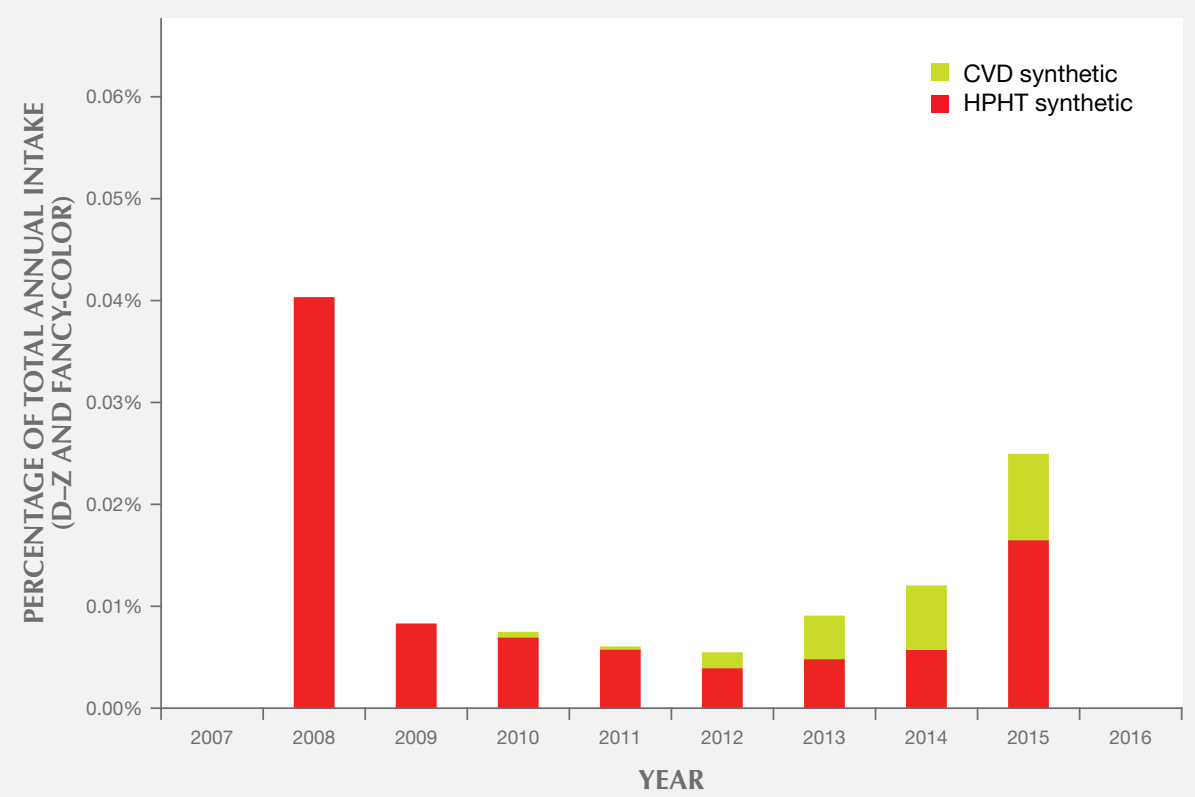

Figure 21. This plot shows the distribution of CVD and HPHT synthetics among all diamonds submitted to GIA for grading. Compared to natural diamonds, the percentage of synthetic diamonds overall is very small. The higher percentages in 2007-2008 are due to the introduction of the GIA Synthetic Diamond Grading Report in early 2007. During this period, GIA received submissions of synthetic diamonds that had been manufactured over the course of many years.

HPHT synthetics with yellow coloration (including yellow, yellow-orange, and yellow-brown) had high percentages of nitrogen-related defects. Pink synthetics, while generally having a lower nitrogen concentration than the yellow synthetics, undergo post-growth coloration treatment that increases the concentration of these nitrogen-related PL defects.

There were also some spectral peaks we were unable to identify (e.g., 536, 707, 712, 912, and $953 \mathrm{~nm}$; not shown), which could also correspond to nitrogen or nickel-related defects or be related to other metal catalysts or other impurities within the source materials. Also present in samples of various colors was the silicon-related defect, $\mathrm{SiV}^{-}(737 \mathrm{~nm}$; D'HaenensJohansson et al., 2011). A significant portion of the type IIb diamonds (37\%) were entirely featureless by PL spectroscopy (figure 20). Several PL features, such as $3 \mathrm{H}$ and peaks at 648.2 and $776.4 \mathrm{~nm}$, are regularly detected in natural type IIb diamonds, yet these peaks are not observed in type IIb HPHT synthetics due to the features' low thermal stability (Eaton-Magaña and Ardon, 2016).

\section{FUTURE}

Figure 21 shows the percentages of CVD and HPHT synthetics out of the total annual intake of $\mathrm{D}-\mathrm{Z}$ and fancy-color diamonds submitted to GIA's laboratory. The overall percentages are quite small—around
$0.01 \%$ in most years. The volume of synthetics was highest in 2007-2008, the first two years after the introduction of GIA's Synthetic Diamond Grading Report, as many years of prior synthetic production were submitted. As mentioned in the Eaton-Magaña and Shigley (2016) survey of CVD synthetics, we expect that the number of HPHT synthetic diamonds submitted will continue to increase, especially at the extreme ends of the weight scale-both melee-sized and greater than 4 carats. Improvements in growth processes are making it easier to grow a large quantity of colorless melee synthetics, or to maintain growth over a long enough period to produce larger crystals.

We predict that in the coming years most HPHT synthetics will be blue or colorless, with fancy pink and fancy yellow colors available but to a lesser extent. Yellow-orange will still be submitted to GIA but in small numbers. There is already an abundance of yellow-orange HPHT synthetics, and these will be an important part of the market for many years. Other interesting products have recently been seen in GIA laboratories, such as an attractive Fancy Deep green HPHT synthetic colored by massive amounts of nickel impurities (Johnson et al., 2017). Quality factors such as carat weight, cut grade of round brilliants, and clarity will likely continue to improve over the coming years. 


\section{CONCLUSION}

Today the HPHT growth process is used to produce colorless or fancy-color synthetic diamonds with high clarity. In recent years, extremes in carat weight—both melee (again, see box B) and larger sizes greater than four carats-have attracted the most attention and made the greatest strides. As growth processes continue to improve, clarity will likely improve, color zoning within fancy-color diamonds will become less noticeable, and the resulting synthetics will likely be visually less distinguishable from pol- ished natural diamonds. Nevertheless, these HPHT synthetics display ultraviolet fluorescence reactions and inclusion features that are unusual in natural diamonds. The results described in this article illustrate how these samples all exhibit spectroscopy features that are quite different from those found in comparable natural diamonds. Based on the use of analytical instruments and access to our large database of gemological information, the synthetic diamonds examined to date by GIA can be readily identified.

\section{REFERENCES}

Ardon T., Batin R. (2016) Lab Notes: HPHT-grown synthetic with strain. $G \uplus G$, Vol. 52, No. 4, pp. 417-418.

Bovenkerk H.P., Bundy F.P., Hall H.T., Strong H.M., Wentorf R.H. (1959) Preparation of diamond. Nature, Vol. 194, No. 4693, pp. 1094-1098, http://dx.doi.org/10.1038/1841094a0

Boyd S.R., Kiflawi I., Woods G.S. (1994) The relationship between infrared absorption and the A defect concentration in diamond. Philosophical Magazine Part B, Vol. 69, No. 6, pp. 1149-1153, http://dx.doi.org/10.1080/01418639408240185

(1995) Infrared absorption by the B nitrogen aggregate in diamond. Philosophical Magazine Part B, Vol. 72, No. 3, pp. 351361, http://dx.doi.org/10.1080/13642819508239089

Breeding C.M., Shigley J.E. (2009) The "type" classification system of diamonds and its importance in gemology. $G \uplus G$, Vol. 45, No. 2, pp. 96-111, http://dx.doi.org/10.5741/GEMS.45.2.96

Collins A.T. (2010) Determination of the boron concentration in diamond using optical spectroscopy. Proceedings of the 61st Diamond Conference, Warwick, UK.

Collins A.T., Williams A.W.S. (1971) The nature of the acceptor centre in semiconducting diamond. Journal of Physics C: Solid State Physics, Vol. 4, No. 13, pp. 1789-1800, http://dx.doi.org/ 10.1088/0022-3719/4/13/030

Deljanin B., Alessandri M., Peretti A., Åström M. (2015) NDT breaking the 10 carat barrier: World record faceted and gemquality synthetic diamonds investigated. Contributions to Gemology, No. 15, pp. 1-7.

D'Haenens-Johansson U.F.S., Edmonds A.M., Green B.L., Newton M.E., Davies G., Martineau P.M., Khan R.U.A., Twitchen D.J. (2011) Optical properties of the silicon split-vacancy center in diamond. Physical Review B, Vol. 84 No. 24, pp. 245208-1245208-14, http://dx.doi.org/10.1103/PhysRevB.84.245208

D’Haenens-Johansson U.F.S., Moe K.S., Johnson P., Wong S.Y., Lu R., Wang W. (2014) Near-colorless HPHT synthetic diamonds from AOTC Group. GÆG, Vol. 50, No. 1, pp. 30-45, http://dx.doi.org/10.5741/GEMS.50.1.30

D'Haenens-Johansson U.F.S., Katrusha A., Moe K.S., Johnson P., Wang W. (2015) Large colorless HPHT-grown synthetic gem diamonds from New Diamond Technology, Russia. $G \uplus G$, Vol. 51,
No. 3, pp. 260-279, http://dx.doi.org/10.5741/GEMS.51.3.260 Dobrinets I.A., Vins V.G., Zaitsev A.M. (2013) HPHT-Treated Diamonds: Diamonds Forever. Springer, Heidelberg, Germany.

Eaton-Magaña S., Lu R. (2011) Phosphorescence in type IIb diamonds. Diamond and Related Materials, Vol. 20, No. 7, pp. 983-989, http://dx.doi.org/10.1016/j.diamond.2011.05.007

Eaton-Magaña S., Ardon T. (2016) Temperature effects on luminescence centers in natural type IIb diamonds. Diamond and Related Materials, Vol. 69, pp. 86-95, http://dx.doi.org/10.1016/ j.diamond.2016.07.002

Eaton-Magaña S., Shigley J. (2016) Observations on CVD-grown synthetic diamonds: A review. $G \uplus G$, Vol. 52, No. 3, pp. 222245, http://dx.doi.org/10.5741/GEMS.52.3.222

Eaton-Magaña S., Ardon T., Zaitsev A.M. (2017) Inclusion and point defect characteristics of Marange graphite-bearing diamonds after high temperature annealing. Diamond and Related Materials, Vol. 71, pp. 20-29, http://dx.doi.org/10.1016/ j.diamond.2016.11.011

Fisher D., Sibley S.J., Kelly C.J. (2009) Brown colour in natural diamond and interaction between the brown related and other colour-inducing defects. Journal of Physics: Condensed Matter, Vol. 21, No. 36, Article 364213, 10 pp., http://dx.doi.org/ $10.1088 / 0953-8984 / 21 / 36 / 364213$

Gaillou E., Post J.E., Rost D., Butler J.E. (2012) Boron in natural type IIb blue diamonds: Chemical and spectroscopic measurements. American Mineralogist, Vol. 97, No. 1, pp. 1-18, http://dx.doi.org/10.2138/am.2012.3925

Hainschwang T., Notari, F., Vadaski E. (2014) The Rhodesian Star: An exceptional asteriated diamond. Journal of Gemmology, Vol. 34, No. 4, pp. 306-315.

Johnson P., Myagkaya E. (2017) Lab Notes: HPHT synthetic diamond with intense green color. $G \uplus G$, Vol. 53, No. 1, pp. 96-98.

Johnson P., Wang W. (2015) Lab Notes: Intense blue diamond with very high boron concentration. $G \uplus G$, Vol. 51, No. 2, pp. 176-177.

Kiflawi I., Mayer A.E., Spear P.M., van Wyk J.A., Woods G.S. (1994) Infrared absorption by the single nitrogen and $A$ defect centres in diamond. Philosophical Magazine Part B, Vol. 69, No. 6, pp. 
1141-1147, http://dx.doi.org/10.1080/01418639408240184

King J.M., Shigley J.E., Guhin S.S., Gelb T.H., Hall M. (2002) Characterization and grading of natural-color pink diamonds. $G \uplus G$, Vol. 38, No. 2, pp. 128-147, http://dx.doi.org/10.5741/ GEMS.38.2.128

King J.M., Shigley J.E., Gelb T.H., Guhin S.S., Hall M., Wang W. (2005) Characterization and grading of natural-color yellow diamonds. Ge G, Vol. 41, No. 2, pp. 88-115, http://dx.doi.org/ 10.5741/GEMS.41.2.88

Kitawaki H., Abduriyim A., Okano M. (2008) Identification of melee-size synthetic yellow diamonds in jewelry. $G \uplus G$, Vol. 44 , No. 3, pp. 202-213, http://dx.doi.org/10.5741/GEMS.44.3.202

Klein P.B., Crossfield M.D., Freitas J.A., Collins A.T. (1995) Donoracceptor pair recombination in synthetic type-IIb semiconducting diamond. Physical Review B, Vol. 51, No. 15, pp. 9634-9642, http://dx.doi.org/10.1103/PhysRevB.51.9634

Lang A.R., Yelisseyev A.P., Pokhilenko N.P., Steeds J.W., Wotherspoon A. (2004) Is dispersed nickel in natural diamonds associated with cuboid growth sectors in diamonds that exhibit a history of mixed-habit growth? Journal of Crystal Growth, Vol. 263, No. 14, pp. 575-589, http://dx.doi.org/10.1016/j.jcrysgro.2003.11.116

Moses T.M., Reinitz I.M., Johnson M.L., King J.M., Shigley J.E. (1997) A contribution to understanding the effect of blue fluorescence on the appearance of diamonds. Ge G, Vol. 33, No. 4, pp. 244-259, http://dx.doi.org/10.5741/GEMS.33.4.244

Shigley J.E. (2008) A review of current challenges for the identification of gemstones. Geologija, Vol. 50, No. 4, pp. 227-236.

Shigley J.E., Fritsch E., Koivula J.I., Sobolev N.V., Malinovsky I.Y., Pal'yanov Y.N. (1993) The gemological properties of Russian gem-quality synthetic diamonds. GÆG, Vol. 29, No. 4, pp. 228248, http://dx.doi.org/10.5741/GEMS.29.4.228

Shigley J.E., Moses T.M., Reinitz I., Elen S., McClure S.F., Fritsch E. (1997) Gemological properties of near-colorless synthetic diamonds. Ge G, Vol. 33, No. 1, pp. 42-53, http://dx.doi.org/ 10.5741/GEMS.33.1.42

Shigley J.E., Abbaschian R., Clarke C. (2002) Gemesis laboratorycreated diamonds. GÆG, Vol. 38, No. 4, pp. 301-309, http://dx.doi.org/10.5741/GEMS.38.4.301
Shigley J.E., McClure S.F., Breeding C.M., Shen A.H.-T., Muhlmeister S.M. (2004) Lab-grown colored diamonds from Chatham Created Gems. Ge G, Vol. 40, No. 2, pp. 128-145, http://dx.doi.org/10.5741/GEMS.40.2.128

Shirey S.B., Shigley J.E. (2013) Recent advances in understanding the geology of diamonds. Ge G, Vol. 49, No. 4, pp. 188-222, http://dx.doi.org/10.5741/GEMS.49.4.188

Smith E.M., Shirey S.B., Nestola F., Bullock E.S., Wang J., Richardson S.H., Wang W. (2016) Large gem diamonds from metallic liquid in Earth's deep mantle. Science, Vol. 354, No. 6318, pp. 1403-1405, http://dx.doi.org/10.1126/science.aal1303

Soonthorntantikul W., Siritheerakul P. (2015) Lab Notes: Near-colorless melee-sized HPHT synthetic diamonds identified in GIA laboratory. $G \uplus G$, Vol. 51, No. 2, pp. 183-184.

Sumiya H., Satoh S. (1996) High-pressure synthesis of high-purity diamond crystal. Diamond and Related Materials, Vol. 5, No. 11, pp. 1359-1365, http://dx.doi.org/10.1016/0925-9635(96) 00559-6

Wang W., Poon T. (2016) Lab Notes: Large blue and colorless HPHT synthetic diamonds. Ge G, Vol. 52, No. 2, pp. 195-196.

Watanabe K., Lawson S.C., Isoya J., Kanda H., Sato Y. (1997) Phosphorescence in high-pressure synthetic diamond. Diamond and Related Materials, Vol. 6, No. 1, pp. 99-106, http://dx.doi.org/ 10.1016/S0925-9635(96)00764-9

Welbourn C.M., Cooper M., Spear P.M. (1996) De Beers natural versus synthetic diamond verification instruments. $G \oplus G$, Vol. 32, No. 3, pp. 156-169, http://dx.doi.org/10.5741/GEMS.32.3.156

Yelisseyev A., Babich Y., Nadolinny V., Fisher D., Feigelson B. (2002) Spectroscopic study of HPHT synthetic diamonds, as grown at $1500^{\circ} \mathrm{C}$. Diamond and Related Materials, Vol. 11, No. 1, pp. 22 37, http://doi.org/10.1016/S0925-9635(01)00526-X

Yelisseyev A., Steeds J.W., Babich Y., Feigelson B. (2006) A new approach to investigation of nickel defect transformation in the HPHT synthetic diamonds using local optical spectroscopy. Diamond and Related Materials, Vol. 15, No. 11/12, pp. 18861890, http://dx. doi.org/10.1016/j.diamond.2006.07.027

Zaitsev A.M. (2003) Optical Properties of Diamond: A Data Handbook. Springer-Verlag, Berlin. 